\title{
The recognition and the constitution of the theorems of closure
}

\author{
François Lê* \\ Post-print version. June 2018
}

\section{Introduction}

\subsection{A category of problems and theorems}

In different ages and places, practitioners of mathematics have distinguished and forged many categories such as disciplinary rubrics, families of objects, and classes of problems. ${ }^{1}$ Accordingly, many historical investigations have been conducted to understand the significance of such categories for the people who created or used them, the dynamics of the research concealed behind their labels, or their role in the development of particular parts of mathematics. For instance, having aimed attention at the corresponding entries in various encyclopedic publications, [Gilain 2010] explained the evolution of the status of "analysis" during the Enlightenment; in another paper, I have tackled the organization of the knowledge linked to a family of objects called "geometrical equations" and the role of this family in the process of assimilation of substitution theory in the second half of the nineteenth century, [Lê 2016]; as for classes of problems, [Chorlay 2010] delineated how the so-called "Cousin problems," coming from complex analysis, were involved in the emergence of sheaf theory in the course of the twentieth century. ${ }^{2}$

If the contents of such categories have often been investigated, such investigations rarely extend to the processes of their creation. ${ }^{3}$ The present article proposes to tackle this question in the case of a category of geometric problems and theorems that have been called Schliessungsprobleme and Schliessungssätze by German-speaking mathematicians since the beginning of the $1870 \mathrm{~s} .{ }^{4}$

\footnotetext{
*Univ Lyon, Université Claude Bernard Lyon 1, CNRS UMR 5208, Institut Camille Jordan, 43 blvd. du 11 novembre 1918, F-69622 Villeurbanne Cedex, France.

${ }^{1}$ Note that in this paper, the word "category" will never refer to its current technical mathematical meaning.

${ }^{2}$ Aside from these recent examples dealing with explicit categories, [Chemla 2009] proved the existence of classes of problems that were seen (but not made explicit) by commentators of the Nine Chapters. Further, the collective project [Bernard 2015] tackled the notion of "series of problems" to designate a specific textual genre characterized by sequences of mathematical questions and answers.

${ }^{3}$ See, however, the descriptions given in [Chorlay 2010, pp. 19-24, 65-66].

${ }^{4}$ I will translate Schliessungsprobleme and Schliessungssätze by "problems of closure" and "theorems of closure." The word Schliessungstheoreme was also used by mathematicians of the time instead of Schliessungssätze, and similarly, although much less frequently, Schliessungsaufgaben sometimes replaced Schliessungsprobleme. Following [Müller 1900, pp. 143, 260, 276, 293], I chose to adopt the same translation for Theorem and Satz on
} 


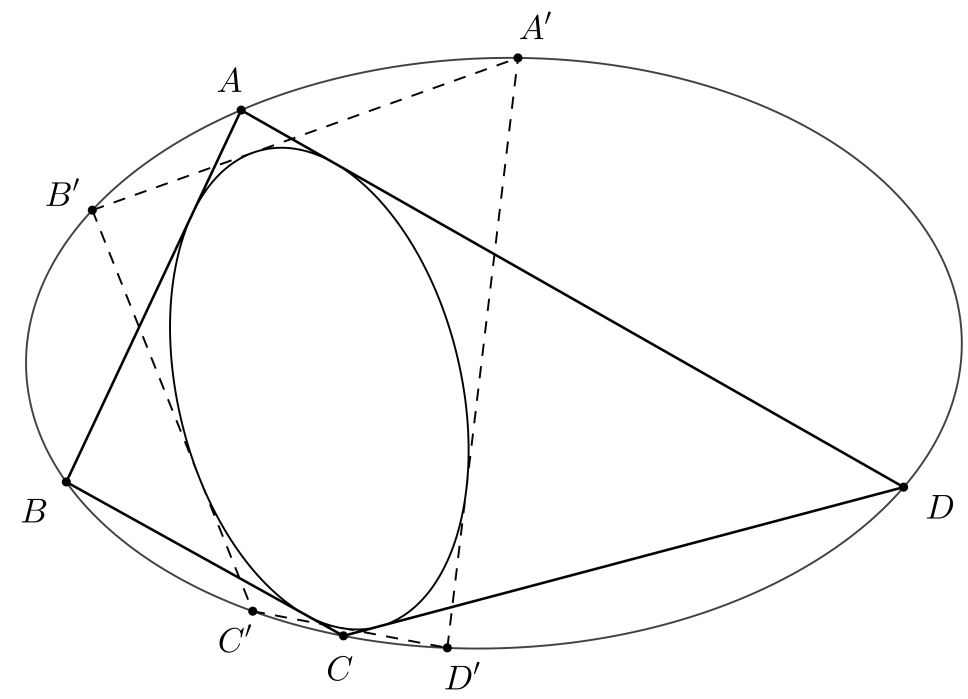

Figure 1 - The theorem of Poncelet: because one starting point $A$ leads to a closed quadrilateral, every starting point (like $A^{\prime}$ ) leads to a closed quadrilateral.

One emblematic example belonging to this category is the problem about polygons and conics that Jean-Victor Poncelet enunciated and solved in his 1822 Traité des propriétés projectives des figures, [Poncelet 1822], and that was recognized in 1876 by the mathematician and historian of mathematics Max Simon as "the most famous of the problems of closure." 5 This problem can be formulated as follows: two conics being given, one starts from a point $A$ on one of them and draws a tangent to the other one, which defines a new point $B$ on the first conic. Continuing this way, one constructs a polygonal line $A B C D \ldots$ The problem is then to determine if it is possible to obtain a closed polygonal line, thus yielding a polygon inscribed in the first conic and circumscribed about the other. Poncelet then proved the theorem that if it is possible to find one such polygon with, say, $n$ sides, then infinitely many polygons with $n$ sides exist, every point on the first conic being the starting point of a closed polygon (see figure 1). ${ }^{6}$

Two general remarks should be made at this point. The first one bears upon the difference between problems and theorems, a difference which can obviously be seen in the existence of the two labels Schliessungsprobleme and Schliessungssätze, and which shaped my explanations in the preceding paragraph. It echoes the distinction inherited from Greek Antiquity: problems primarily link to constructions of objects having given properties, whereas theorems mostly relate to the statement of properties of given objects. ${ }^{7}$ That being said, we will see that the vast majority of the mathematicians involved in the activities

one hand, and for Problem and Aufgabe on the other hand.

5"[Das] bekanntest[e] der Schliessungsproblemen." [Simon 1876, p. 303]. As has been remarked in [Bos et al. 1987, pp. 311-313], Poncelet proved this theorem already in 1813-1814, yet with different methods as those employed in the Traité. However, we will see that the authors who worked on the theorems of closure mostly cited Poncelet's 1822 book. On the Traité, see for instance [Friedelmeyer 2011; Nabonnand 2015].

${ }^{6}$ In this paper, all the figures whose caption do not contain a citation are mine.

${ }^{7}$ More detailed explanations are given in [Vitrac 1990, pp. 133-137]. 
surrounding closure problems and theorems expressed no strong distinction between the two notions, and sometimes even amalgamated and interchanged them. In any case, it is important to note that the presence of two kinds of labels neither indicates the existence of two distinct categories, nor reflects a special organization of the mathematical work. ${ }^{8}$ On the contrary, we will see that the labels Schliessungsprobleme and Schliessungssätze did refer to one family of propositions which were sometimes formulated as problems, sometimes as theorems, without affecting the mathematical work itself.

The second remark is that several historical investigations have already depicted the works of Poncelet on his theorem, as well as those of his identified predecessors and of some of the mathematicians who tackled the same theorem throughout the nineteenth and the twentieth centuries. ${ }^{9}$ If, therefore, the present paper will meet these investigations here and there, its aim is different from theirs, as its attention will be directed to the process through which the category associated with the name Schliessungssätze was constituted during the nineteenth century. Hence other theorems than that of Poncelet will be considered-like the celebrated theorem of Jacob Steiner [1826] about chains of circles that are tangent to each other and to two given circles-, and I will analyze how they have been connected to one another and, at some point, recognized to be elements of a bigger whole. ${ }^{10}$

Because the aim here is to understand the mechanisms that have underlain the recognition and the constitution of the theorems of closure, the focus will be not so much on the whole technical content of the mathematical works in which the elements of the category were dealt with, but rather on the traces of the emergence and the strengthening of this category. ${ }^{11} \mathrm{~A}$ notable feature is that its constitution has been a collective process which took place during a great part of the nineteenth century: we will see that when the labels Schliessungsprobleme and Schliessungssätze appeared in the writings of mathematicians in the 1870s, they were used to designate problems and theorems that had been tackled by others decades ago (like Poncelet and Steiner themselves, but also Carl Gustav Jacob Jacobi [1828], who used the theory of elliptic functions to tackle Poncelet's theorem), without yet being explicitly seen as instances of a single family. We will also see that the creation and the use of encompassing words went along with statements of new theorems obtained by extensions, observations of analogies, ${ }^{12}$ or searches for technical unifying points of view were the features that conducted and sustained the constitution of the theorems of closure as a proper category. In

${ }^{8}$ Therefore, the situation differs from what is described in [Goldstein 2013], where the emphasis put on problems marks a particular way of communicating within Marin Mersenne's correspondence. Moreover, the English-speaking authors that I encountered did not employ the phrases "theorems of closure" and "problems of closure." Instead, they often used the term "porism," another term coming from Greek Antiquity and designating a kind of proposition somewhat situated between "problem" and "theorem." Even if this distinction was thus more obvious for these authors, it did not seem to impact the organization of their work. I will elaborate on the specificity of the English (and the French) situation later in this text.

${ }^{9}$ See [Bos et al. 1987; Del Centina 2016; Friedelmeyer 2007]. Because the theorem of Poncelet has been approached with the help of elliptic functions in the course of the nineteenth century, it also appears in historical studies devoted to these functions, or, more specifically, to their link with geometry. See for instance [Barbin and Guitart 2001; Bottazzini and Gray 2013].

${ }^{10}$ [Del Centina 2016, p. 78 sqq.] briefly describes some other closure theorems, but their link with that of Poncelet and the dynamics of their constitution are not clearly delineated.

${ }^{11}$ Nevertheless, some of these traces are to be found within mathematical details, and we will enter into the technique when needed.

${ }^{12}$ About the different roles of analogy in the history of mathematics, see [Knobloch 1991] and [Durand-Richard 2008], several contributions of which also deal with other sciences. 
particular, we will see that between 1876 and 1879, three mathematicians presented their own unifying point of view: Friedrich August based his approach on the use of adequate geometric projections, while Simon saw the elliptic functions as the objects explaining the unity of the theorems of closure, and Adolf Hurwitz justified this unity with the help of a certain "fundamental theorem of algebra."

\subsection{The theorems of closure in the Encyklopädie; creation of a corpus of investigation}

As explained above, the label Schliessungssätze and its variants have been used by mathematicians in their published production since the 1870s. These labels also appear in the titles of different sections of the famous Encyklopädie der mathematischen Wissenschaften mit Einschluss ihrer Anwendungen, which suggests that, at least for some (influential) mathematicians, they did refer to an identified category used in synthetic presentations of certain topics at the beginning of the twentieth century. ${ }^{13}$ All of these sections are contained in the volumes of geometry of the Encyklopädie; more precisely, Max Zacharias' chapter, devoted to elementary geometry, contains a section entitled "Kreis und Kugel. Schliessungsaufgaben, Inversion, Pol und Polare" [Zacharias 1913, §17]; the chapter on conics, written by Friedrich Dingeldey, has three sections called "Schliessungssatz von Poncelet," "Zusammenhang des Schliessungsproblems mit den elliptischen Funktionen," and "Weitere Arbeiten zum Schliessungstheorem" [Dingeldey 1903, §§26, 27, 28]; Otto Staude's chapter on quadric surfaces has a section named "Schliessungssätze" [Staude 1904, §123]; finally, Gustav Kohn's chapter dealing with cubic and quartic curves contains a section entitled "Schliessungsprobleme, eingeschriebene Polygone und Konfigurationen" [Kohn 1908].

It is interesting to remark that, according to the titles of the other sections of these chapters, the theorems of closure appear to be on the same level as other topics that may be more familiar to the present-day reader. For instance, one finds sections devoted to "constructions with ruler and compass" and to the "cyclotomy and the problems of Apollonius and of Malfatti" ( $\S \S 23,24$ of Zacharias' chapter); to the "axis of conics and the imaginary circular points" and to Pascal's theorem ( $\$ 13,18$ of Dingeldey's chapter); to the "canonical equations and shapes" of quadric surfaces and to the "parametric representation" of the intersections of two such surfaces ( $\$ \S 10,113$ of Staude's chapter); to the "inflection points of a cubic curve" and to the "univocal algebraic transformations of elliptic curves" ( $\$ \$ 15,37$ of Kohn's chapter).

Now, to create a corpus of investigation on the theorems of closure, I gathered all the references given in the six mentioned sections of the Encyklopädie dealing with these theorems. Moreover, because Zacharias cites a section of the book of Simon on the history of elementary geometry as a bibliographical reference, I added the texts listed in this section, called "Schliessungsproblem" [Simon 1906, pp. 108-109]. ${ }^{14}$

\footnotetext{
${ }^{13}$ Let us recall that the Encyklopädie is the fruit of a collaborative project launched by Felix Klein at the very end of the nineteenth century. The objective was to give a view on the mathematical research of the time, and to draw up a report on the mathematical knowledge of the nineteenth century. The geometric volumes, which interest us here, have been edited by Franz Meyer and Hans Mohrmann. About the Encyklopädie, see [Gispert 1999; Tobies 1994].

${ }^{14}$ Simon's book was initially meant to be included in the Encyklopädie, but this eventually did not happen because the references given therein were too imprecise, see [Volkert 1994, p. 79].
} 
This corpus contains 130 texts, written by 87 authors, and whose dates of publication extend from 1749 to 1907 . As the diagram in figure 2 shows, only a few sporadic texts are dated from the eighteenth century, and a small group of texts were published between 1822 and 1831. The majority of the contributions appeared between 1845 and 1907, with a notable peak during the decade 1875-1885. Among the 130 texts, 60 are written in German, 32 in French, 30 in English, 4 in Italian, and 4 in Latin. The corpus includes 15 books, most of them treatises of advanced mathematics of their time, like Poncelet's Traité des propriétés projectives des figures [Poncelet 1822] or Georges-Henri Halphen's Traité des fonctions elliptiques et de leurs applications [Halphen 1886]. About a fifth of the 115 articles are distributed in journals aimed at teachers or students of mathematics. ${ }^{15}$ The other articles appeared mostly in Crelle's Journal für die reine und angewandte Mathematik (25 articles), but also in Mathematische Annalen (8 articles), Quarterly Journal of Pure and Applied Mathematics (7 articles), Journal de mathématiques pures et appliquées and Proceedings of the London Mathematical Society (6 articles each). ${ }^{16}$ If almost all of the 87 authors published once or twice in the corpus, Arthur Cayley and Jacob Steiner are two exceptional cases, with 10 and 7 papers respectively. As will be seen, these numbers reflect different situations: while Cayley's publications exclusively relate to Poncelet's polygons and are often supplements, corrections, or syntheses of one another, those of Steiner appear to be more independent from each other and deal with a large range of geometric problems and theorems. Let us finally note that the corpus contains papers of Simon and of Staude, two of the authors of the reviews we used to create it. The corpus thus reflects the point of view of some of the mathematicians who researched the subject of the theorems of closure. ${ }^{17}$

The description of the corpus will be chronological, in order to delineate the dynamic constitution of the category of closure theorems: in doing so, we will see that taking for granted the division of the four chapters of the Encyklopädie would be misleading, for it neither reflects a chronological progression, nor displays the many links existing between works of the corpus coming from different chapters. Accordingly, four sections will be devoted to four moments of this constitution: the research on several theorems that were treated quite independently from each other (1749-1864), the first mentions of a certain class of problems and theorems, called "Schliessungsprobleme" shortly after (1864-1870), the search for unifying technical frameworks of the theorems of closure (1876-1879), and finally the production of many works revisiting the already-known theorems of closure, or creating and investigating extensions of them (1880-1907). After these four sections, I will conclude with a reflection on the process of categorization that underlain the progressive constitution of the theorems of closure, specifically in the light of Ludwig Wittgenstein's notion of family resemblance.

\footnotetext{
${ }^{15}$ Among these "intermediate" journals, the two ones which gather the greatest number of papers of the corpus are Zeitschrift für Mathematik und Physik and Nouvelles Annales de mathématiques, each representing 6 papers. Most of the articles of the corpus published in intermediate journals come from Simon's history of elementary geometry. On Nouvelles Annales de mathématiques, see [Rollet and Nabonnand 2013].

${ }^{16}$ The total number of non-intermediate journals in the corpus is 26. Each of those which are not cited here represents less than 6 articles.

${ }^{17}$ Moreover, as has been noted by one of the reviewers, one should keep in mind that some of the authors of our sources (Zacharias, Dingeldey, Staude, Kohn, and Simon) might have been more systematic than the others in their bibliographical research, so that the corpus might also reflect such dissymmetries.
} 


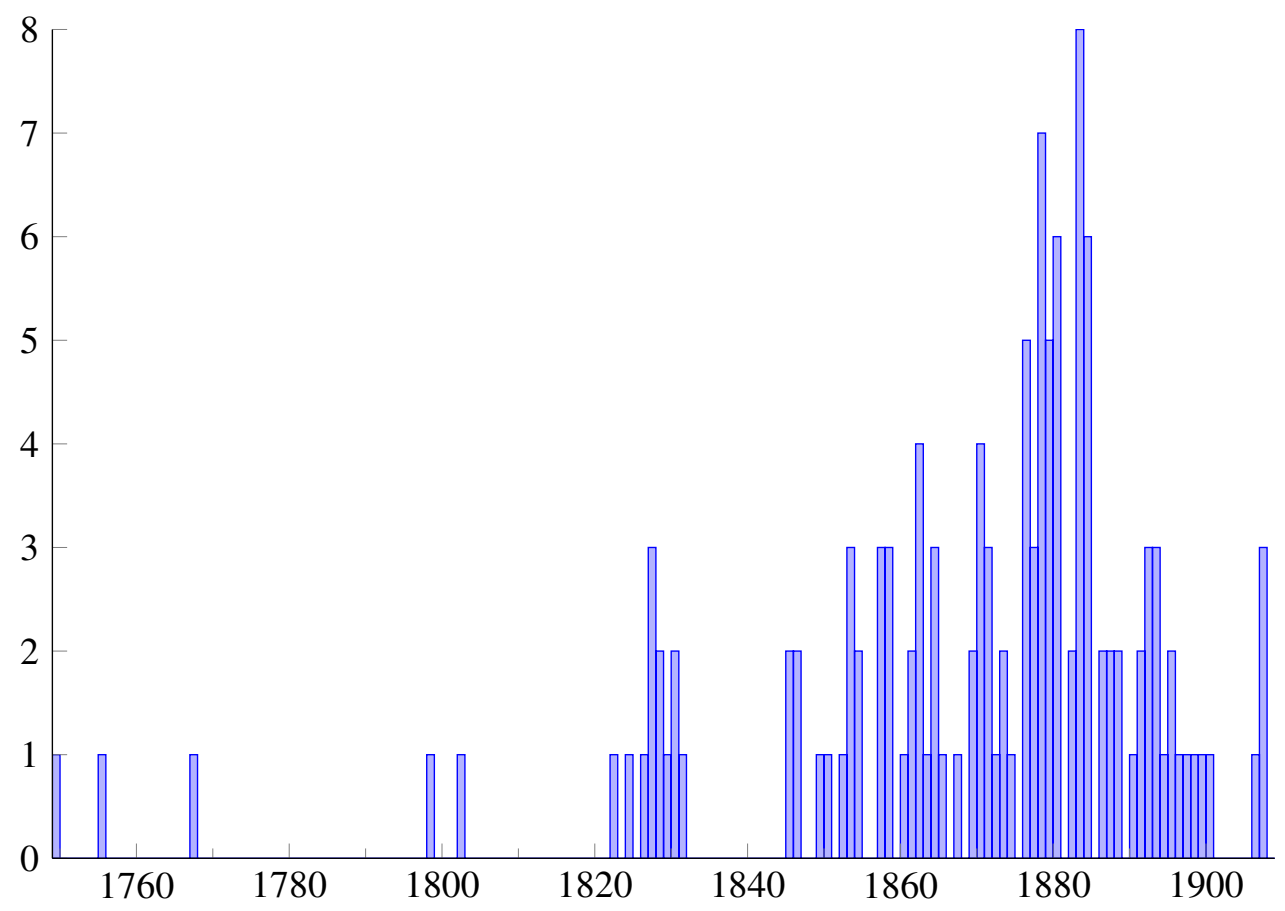

Figure 2 - Number of publications in the corpus.

\section{Several theorems and their extensions, 1749-1864}

\subsection{Poncelet's polygons and Steiner's chains of circles}

The very first publications of our corpus constitute what has been called the "prehistory" of Poncelet's theorem on the polygons inscribed in a conic and circumscribed about another conic, a "prehistory" lasting from 1749 to $1802 .{ }^{18}$ These publications exclusively pertained to the case where the two conics are two circles and the considered polygons have a definite number of sides between 3 and 8. For instance, William Chapple [1749] proved that if it is possible to "interscribe" 19 a triangle between two circles, then it is possible to interscribe infinitely many of them. In that case, he found the formula

$$
a^{2}=R^{2}-2 r R
$$

linking the radii $r$ and $R$ of the exterior and the inner circles with the distance $a$ between the centers of the two circles. A similar formula in the case of a quadrilateral interscribed between two circles was proved by Nicolas Fuss in a 1798 paper, [Fuss 1798]; a few years later, Fuss also tackled the cases of pentagons, hexagons, heptagons, and octagons, but he

\footnotetext{
${ }^{18}$ See [Bos et al. 1987, pp. 291-297; Del Centina 2016, pp. 5-19]. These references describe works of Leonhard Euler, John Landen, and Simon Antoine Jean Lhuiller, which belong to our corpus but which will not be discussed here. Remark that the word "prehistory" has been used in these references to designate works that had been published before the research of Poncelet himself. Here I consider them as part and parcel of the history of the theorems of closure.

${ }^{19}$ This neologism is borrowed from [Bos et al. 1987]. A polygon is said to be interscribed between two curves if it is circumscribed about one of these curves and inscribed in the other one.
} 


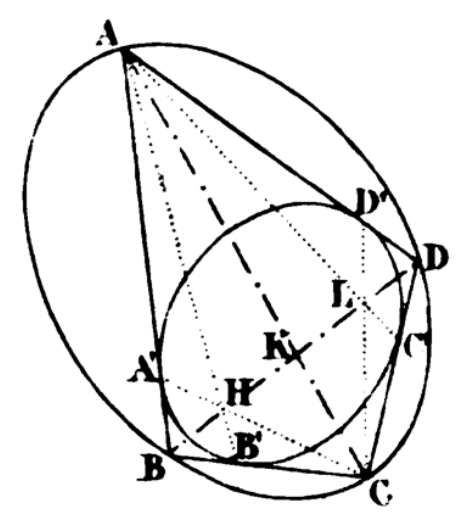

Figure 3 - A case of a closed quadrilateral $A B C D$ interscribed between two ellipses. The point $K$, defined as the intersection of the diagonals, is the same for all the interscribed quadrilaterals. This figure is one of the many that Poncelet included at the end of the Traité, [Poncelet 1822, fig. 103].

could only obtain such metric formulas (expressed with $r, p=R+a$, and $q=R-a$ ) when these polygons have particular symmetries, [Fuss 1802].

Jean-Victor Poncelet published his Traité des propriétés projectives des figures in 1822, a treatise whose main part culminated with the statement and the proof of the theorem about the polygons interscribed between two conics. ${ }^{20}$ The theorem was expressed in the following words:

When a polygon is inscribed in a conic and circumscribed about another one, there exist infinitely many other polygons having the same property; or rather, every polygon one would try to describe according to these conditions would close by itself on these curves.

Conversely, if it happens that, trying to inscribe in a conic a polygon whose sides touch another conic, this polygon does not close by itself, there would necessarily be no other polygon having this property. ${ }^{21}$ [Poncelet 1822, p. 361]

Although it is not clearly expressed in this extract, Poncelet's theorem includes the fact that if closed polygons exist, they all have the same number of sides. Poncelet also investigated further properties of particular closed polygons: for example, he proved that the diagonals of all the quadrilaterals interscribed between two conics meet in the same point (see figure 3).

Shortly after the publication of Poncelet's Traité, the French mathematician J. B. Durrande wrote an article, which aimed at proving diverse properties of triangles, quadrilaterals, pentagons, and hexagons interscribed between two circles [Durrande 1823/1824].22 The

${ }^{20}$ The section of this book about interscribed polygons is followed by a Supplément, which relates to geometry in the three-dimensional space.

21 "Quand un polygone quelconque est à la fois inscrit à une section conique et circonscrit à une autre, il en existe une infinité de semblables qui jouissent de la même propriété à l'égard des deux courbes; ou plutôt, tous ceux qu'on essaierait de décrire, à volonté, d'après ces conditions, se fermeraient d'eux-mêmes sur ces courbes. Et réciproquement, s'il arrive qu'en essayant d'inscrire à volonté, à une section conique, un polygone dont les côtés en touchent une autre, ce polygone ne se ferme pas de lui-même, il ne saurait nécessairement y en avoir d'autres qui jouissent de cette propriété."

${ }^{22}$ Other works of Durrande are described and analyzed in [Lorenat 2017]. 
article also contained a proof of the theorem of Poncelet in the particular case of triangles interscribed between two circles:

When a triangle is at the same time circumscribed about a circle and inscribed in another circle, an infinity of other triangles can be at the same time circumscribed about the first of these circles and inscribed in the second one. ${ }^{23}$ [Durrande 1823/1824, p. 52]

After having remarked that this result could serve to derive the "general theorem [for triangles and conics] due to Monsieur Poncelet, who even extended it to any polygon," 24 Durrande proposed another theorem, about tetrahedrons and spheres:

If a tetrahedron is at the same time circumscribed about a sphere and inscribed in another sphere, an infinity of other tetrahedrons can be at the same time circumscribed about the first one and inscribed in the second one. ${ }^{25}$ [Durrande 1823/1824, p. 52]

The nearly exact same wordings of Durrande's two theorems reveals how similar they appeared to him. Yet Durrande did not simply analogically extend the first theorem to space by a mere replacement of the words "triangles" and "circles" by "tetrahedrons" and "spheres": he proved the spatial theorem with a combination of the planar one and of an appropriate projection on a plane [Durrande 1823/1824, p. 53].

As we will see, such extensions and interdependence of theorems occurred at many places in the corpus, and we argue that they are one of the factors that implicitly and gradually brought these theorems into a coherent whole.

Between 1826 and 1828, Steiner published several articles, one of them describing properties of particular polygons interscribed between circles, while the others presented investigations about a theorem that would later be recognized as one of Steiner's Schliessungssätze. ${ }^{26}$ This theorem was stated and proved in [Steiner 1826], a paper devoted to diverse problems involving intersections and contacts of circles, and to the development of several geometric notions (like those of point of similitude, and of common power of two circles) meant to solve them. As Steiner explained in the introduction, his research had been motivated by the Apollonius problem (to find a circle tangent to three given circles), the Malfatti problem (to inscribe three tangent circles to a triangle), a theorem attributed to Pappus (to determine relations between distances linked to two tangent circles inscribed in the space between two other tangent circles), as well as "diverse porisms, and the purely geometric consideration on curves and surfaces of the second degree." 27 The theorem we are interested in here was related to chains of circles in the plane:

\footnotetext{
23“'Lorsqu'un triangle est, à la fois, circonscrit à un cercle et inscrit à un autre cercle, une infinité d'autres triangles peuvent être, à la fois, circonscrits au premier de ces cercles et inscrits au second."

24" 'On peut déduire de ce qui précède le théorème général que voici, dû à M. Poncelet, qui l'a même étendu à un polygone quelconque." [Durrande 1823/1824, p. 52].

${ }^{25}$ "Si un tétraèdre est, à la fois, circonscrit à une sphère et inscrit à une autre, une infinité d'autres tétraèdres pourront aussi, à la fois, être circonscrits à la première et inscrits à la seconde."

${ }^{26}$ See for instance the chapter of the Encyklopädie from which we started, [Zacharias 1913, p. 1026].

${ }^{27}$ “... verschiedenen Porismen und der rein geometrische Betrachtung der Curven und Flächen zweiten Grades" [Steiner 1826, p. 161]. Steiner did not explain what he meant by "porism," nor did he explain what results were aimed at. For a thorough description of the first part of Steiner's paper, and especially in the perspective of his treatment of the Apollonius problem, see [Lorenat 2016, pp. 422-427]. About the Malfatti problem, see [Lorenat 2012].
} 


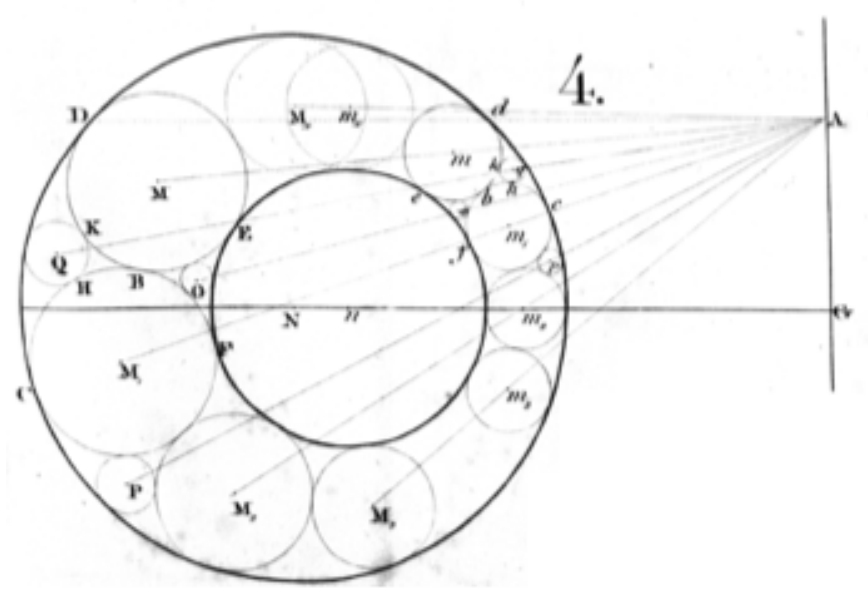

Figure 4 - Steiner's drawing of chains of circles, extracted from the table of illustrations at the end of the paper [Steiner 1826].

Let us suppose that the gap between two circles $n, N$ (one of them lying within the other) is commensurable for a given chain of circles $M, M_{1}, M_{2}, \ldots, M_{x}$ which are all tangent to the two given ones and touch one another consecutively; that is, let us suppose that the chain is composed of $x+1$ members making $u$ turns around the inner circle such that the last circle $M_{x}$ is tangent to the first one, $M$. Then the same gap is commensurable for each chain of circles $m, m_{1}, m_{2}, \ldots, m_{x}$, of which the first member may be chosen at will; moreover, the last chain is also composed of $x+1$ members making $u$ turns around the inner circle. ${ }^{28}$ [Steiner 1826, p. 256]

In other words, this theorem states that if it is possible to insert, between two given circles, a closed chain of tangent circles, then every chain of tangent circles lying between the two given ones closes on itself, is composed with the same number of circles, and makes the same number of turns around the inner circle (see figure 4, or figure 6 below).

After having completed the proof of this theorem, Steiner wrote that "analogous" theorems held when considering chains of spherical circles tangent to two given spherical circles, ${ }^{29}$ or chains of spheres tangent to given spheres [Steiner 1826, p. 257]. Yet, Steiner neither proved these extensions, nor even precisely stated them-other mathematicians would return to these questions later.

Nevertheless, Steiner delved into diverse properties of such chains of spherical circles and of spheres, alongside chains of planar circles, in subsequent papers. One of the questions was to determine metric relations existing between the data of these situations when closed chains exist. In the case of circles in a plane, Steiner asserted that if the radii of the inner and

\footnotetext{
28"Ist der Zwischenraum zwischen zwei [...] in einander liegenden Kreisen $n, N$ für eine bestimmte Reihe Kreise $M, M_{1}, \ldots, M_{x}$, von denen jeder jene beiden ungleichartig berüht, und welche einander der Ordnung nach berühren, commensurabel, d.h., besteht die Reihe aus $x+1$ Gliedern, welche $u$ Umläufe bilden, und berüht der letzte Kreis $M_{x}$ wiederum den ersten $M$ : so ist derselbe Zwischenraum für jede beliebige Reihe Kreise $m, m_{1}, m_{2}, \ldots, m_{x}$, wo man auch das Anfangsglied $m$ annehmen mag, commensurabel; und es besteht die letztere Reihe ebenfalls aus $x+1$ Gliedern, welche $u$ Umläufe bilden, wie jene erstere Reihe." In all our quotations, the italics are the original ones (except when we have kept non-English words in the translations).

${ }^{29}$ Spherical circles are circles drawn on a sphere, or, equivalently, intersections of a sphere with planes.
} 
outer circle are $r$ and $R$, if the distance between their centers is $d$, and if there exists a closed chain made of $m$ circles and making $n$ turns around the inner circle, then

$$
(R-r)^{2}-4 r R \tan ^{2} \frac{n}{m} \pi=d^{2} .
$$

He immediately added that "the same things occur for circles drawn on the surface of a sphere; the equation is then

$$
\cos (R-r)-2 \sin r \sin R \tan ^{2} \frac{n}{m} \pi=\cos d,{ }_{30}
$$

and he also stated such a formula in the case of chains of spheres.

These successive extensions and analogies of the theorems of existence of closed chains, and of several additional properties like those related to metrical relations, as well as their close textual contact within the same paper, suggest that Steiner saw the three theorems on the chains of circles and of spheres as analogous. However, the absence of proofs of the extended theorems prevent us to understand this analogy more precisely: was it perceived on the basis of the resemblance of their wordings and on the similar nature of the involved geometric objects, or was it built upon uniform methods of proof, for instance?

As we wrote before, Steiner was at the same time interested into Poncelet's polygons interscribed between circles, and he notably published results about metrical relations for these polygons in the paper [Abel, Clausen, and Steiner 1827]. There, he gave the equation $a^{2}=R^{2}-2 r R$ expressing the existence of a triangle interscribed between two circles, as well as the formulas corresponding to quadrilaterals, pentagons, hexagons, and octagons. ${ }^{31}$ to give one example, the case of the quadrilateral yielded

$$
\left(R^{2}-a^{2}\right)^{2}=2 r^{2}\left(R^{2}+a^{2}\right) .
$$

After having listed these formulas, Steiner turned to the case of a spherical quadrilateral interscribed between two spherical circles: he asserted that if such a quadrilateral exists, then

$$
\left(\cos ^{2}(r+a)-\cos ^{2} R\right)\left(\cos ^{2}(r-a)-\cos ^{2} R\right)=\sin ^{4} r \cos ^{4} R .
$$

Hence Steiner proceeded to the same kind of extension as he had done for the chains of circles, passing from planar quadrilaterals interscribed between two circles to the corresponding spherical objects.

Steiner did not explicitly express any idea of unity between the problem of the polygons interscribed between two circles and that of the chains of circles, nor did he establish technical features (like projections) explaining how to pass from problem to the other. Yet the structure we just described - treating the planar cases before extending them by analogy to spherical objects, searching for metrical relations linking the same constants-suggests that Steiner perceived them as fitting into a certain common frame. ${ }^{32}$

\footnotetext{
30"Les mêmes choses ont lieu pour des cercles tracés sur la surface d'une sphère; l'équation est alors [...]". [Steiner 1827/1828, p. 380].

${ }^{31}$ Steiner did not mention the works of Chapple and Fuss that we described above. Moreover, Steiner mistakenly attributed the triangle formula to Euler in [Steiner 1827, p. 96], see [Bos et al. 1987, p. 297].

${ }^{32}$ The fact that the metrical relations in both cases of the chains of circles and of interscribed polygons look
} 


\subsection{Entrance of elliptic functions}

The problem of the polygons interscribed between two circles was taken up again in a publication of Jacobi of 1828, in which the latter showed how to use the theory of elliptic functions into this problem [Jacobi 1828]. ${ }^{33}$ Let us recall that elliptic functions are essentially the reciprocal functions of the elliptic integrals of the first kind

$$
u=\int_{0}^{\theta} \frac{\mathrm{d} \vartheta}{\sqrt{1-k^{2} \sin ^{2} \vartheta}}
$$

where $k$ is a real number in ]0, 1 [ called the module of the integral. The upper bound $\theta$ is called the amplitude of $u$, denoted by $\theta=\operatorname{am}(u)$, and one defines the elliptic functions sn, cn, and dn with the formulas ${ }^{34}$

$$
\operatorname{sn}(u)=\sin \operatorname{am}(u), \quad \operatorname{cn}(u)=\cos \operatorname{am}(u), \quad \operatorname{dn}(u)=\sqrt{1-k^{2} \operatorname{sn}^{2}(u)} .
$$

These functions, defined at first in a real neighborhood of 0 , can be extended as complex functions having two periods, which are independent over $\mathbf{R}$ and are expressed as adequate integral combinations of

$$
K=\int_{0}^{\pi / 2} \frac{\mathrm{d} \vartheta}{\sqrt{1-k^{2} \sin ^{2} \vartheta}} \quad \text { and } \quad K^{\prime}=\int_{0}^{\pi / 2} \frac{\mathrm{d} \vartheta}{\sqrt{1-(1-k)^{2} \sin ^{2} \vartheta}}
$$

This property of periodicity is the one that lay at the core of Jacobi's approach.

More precisely, Jacobi considered two circles of radii $r$ and $R$, and noted $a$ the distance between their centers. Then he defined a module $k$ and a constant $c$ depending only on $R, r$, and $a$, and he demonstrated that the existence of one closed $n$-gon making $\ell$ turns around the inner circle is equivalent to the condition $c=2 \ell K / n$. The theorem of Poncelet, which was quoted by Jacobi from the Traité, followed from the fact that this condition is independent from the chosen starting point of the polygonal line, so that the closure of one $n$-gon implies that of every $n$-gon (starting from any point). Jacobi also explained how to obtain the metrical formulas that Steiner had listed in [Abel, Clausen, and Steiner 1827, p. 289]: he indicated that these formulas could be derived from the equality $c=2 \ell K / n$ when expressing the constants $c$ and $K$ with the numbers $r, R$, and $a .^{35}$

alike may reinforce this idea, but Steiner did not comment on this resemblance. As Jemma Lorenat points out to me, Steiner proceeded to similar extensions for the Malfatti problem and the Apollonius problem, and other geometric situations were also treated at first for circles, and were then extended to the case of ellipses and to that of general conics. Thus it seems that such a practice of successive extensions was not characteristic of the problem of chains of circles. See also [Chemla 1998] for a description of the same kind of extensions in some works of Lazare Carnot of the very beginning of the nineteenth century.

${ }^{33}$ As has already been noted by historians, Poncelet later wrote that Jacobi had been encouraged by Steiner himself to make use of elliptic functions in order to tackle the problem of the interscribed polygons. See for instance [Bos et al. 1987, p. 322], and [Poncelet 1862, p. 481] for the story told by Poncelet.

${ }^{34}$ This way of defining elliptic functions is the one adopted in Jacobi's famous Fundamenta nova theoriae functionum ellipticarum [Jacobi 1829], published shortly after the paper we discuss here, but the notations sn, cn, dn have been introduced in 1838 by Christoph Gudermann. See for instance [Bottazzini and Gray 2013, pp. 35-49, 344-346].

${ }^{35}$ Jacobi did not carried out the corresponding computations. However, he proved that the formulas given by Steiner are in concordance with those given by Fuss (who used the quantities $r, p=R+a$, and $q=R-a$ ). 
This article of Jacobi is one of the most frequently cited texts by other mathematicians in the corpus: even though Jacobi only tackled the polygons of Poncelet in the case of two circles, he was still cited in works related to other problems because he was identified as the first to introduce elliptic functions in order to treat such a problem.

For instance, elliptic functions were used by Jacobi's student Friedrich Richelot, in a paper published in 1830, [Richelot 1830]. Specifically, Richelot tackled again the problem of the polygons interscribed between two circles, and showed how to deduce metric relations for a $2 n$-gon from the relations for a $n$-gon. Still working with elliptic functions, he then proved the spherical equivalent of Poncelet's theorem, and managed to find metrical formulas for spherical $n$-gons, with $n=3,4,5,6,8 .^{36}$ Hence Richelot proceeded to the same kind of extension as Steiner had done, passing from the planar case to the spherical one, and searching for metrical relations in this new situation.

Apart from two papers of Thomas Clausen related to chains of circles and of spheres, our corpus does not contain any publication between 1830 and 1845, when a French translation of Jacobi's paper by Olry Terquem was published, [Jacobi 1845].

\title{
2.3 Polygons inscribed in cubics and in bidonal quartics
}

Two new geometric situations appeared in 1846 in a publication of Steiner which, in the image of many other ones, is basically a list of theorems without proof, [Steiner 1846]. One of them was related to polygons inscribed in a cubic curve, ${ }^{37}$ whose sides alternatively pass through two fixed points of the curve (see figure 5). In Steiner's words:

\begin{abstract}
Let us take two fixed points $P$ and $Q$ on a curve of the third order, and let us consider another arbitrary point $A$ on it. The straight line $P A$ being drawn, it intersects the curve in a third point $B$; the straight line $Q B$ being then drawn, it cuts the curve in a third point $C$; the line $P C$ being then drawn, it meets the curve in a third point $D$ [etc.]; in this manner is created a polygon $A B C D E F G \ldots$ inscribed in the curve, whose sides alternatively pass through the two fixed fundamental points $P$ and $Q$, and which either $1^{\circ}$ does not close, as long as one carries on the construction, or $2^{\circ}$ closes, having then an even number of sides $2 n$. In the latter case, the following theorem holds:
\end{abstract}

"If the polygon closes itself, then it always closes and has always the same number of sides $2 n$, the first point A being chosen at will on the curve." 38 [Steiner 1846, p. 182]

\footnotetext{
${ }^{36}$ Richelot would simplify the formulas he found there almost twenty years later, again by using elliptic functions [Richelot 1849].

${ }^{37}$ A cubic curve, also called a "curve of the third order," is a curve that can be defined by a polynomial equation of degree 3. We will also deal with binodal quartic curves, that is, curves defined by a polynomial equation of degree 4 and having two nodes (i.e. singular points where two branches of the curve intersect transversally).

38"Werden in einer Curve dritter Ordnung zwei beliebige Puncte $P$ und $Q$ als fest genommen, wird ferner in derselben ein willkürlich Punct $A$ angenommen und die Gerade $P A$ gezogen, welche der Curve zum dritten Male in einem Punct $B$ begegnet, wird sodann weiter die Gerade $Q B$ gezogen, welche die Curve zum dritten Male in einem Punct $C$ schneidet, wird ferner die Gerade $P C$ gezogen, welche die Curve in einem neuen Punct $D$ trifft [usw.], so entsteht ein der Curve eingeschriebenes Polygon $A B C D E F G$..., dessen Seiten der Reihe nach abwechselnd durch die festen Fundamentalpuncte $P$ und $Q$ gehen, und welches entweder $1^{\circ}$ sich nicht schließt, wie lange auch die Construction fortgesetzt werden mag, oder $2^{\circ}$ sich schließt und dann eine gerade Zahl $2 n$ von Seiten hat. Im letzern Falle findet folgender Satz statt: ,Wenn das Polygon sich schließt, so schließt sich immer und hat stets die nämliche Seitenzahl 2n, man mag die erste Ecke A desselben in der Curve annehmen, wo man will."
} 

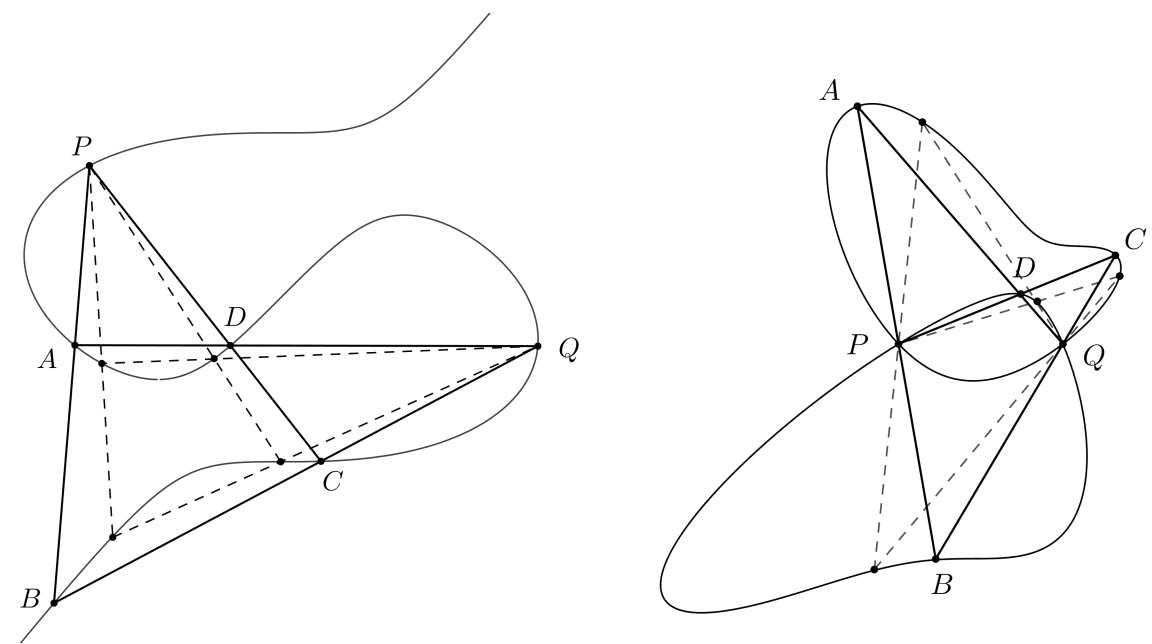

Figure 5 - Quadrilaterals of Steiner inscribed in a cubic (on the left) and in a binodal quartic (on the right), whose sides alternatively pass through two fixed points $P$ and $Q$.

Let us remark that the form of this theorem obviously recalls those about Poncelet's polygons and Steiner's chains of circles, especially because it provides the alternative of the nonexistence of closed $2 n$-gons or the existence of an infinity of them. Furthermore, as in Poncelet's statement, Steiner stressed the possible closure of an iterative construction: this feature is certainly what would later be conveyed by the choice of the labels Schliessungssätze and Schliessungsprobleme.

After having stated this theorem, Steiner also listed several properties of closed quadrilaterals, hexagons, and decagons. For instance, he asserted that if two fixed points $P$ and $Q$ generate a closed quadrilateral, then the tangents to the cubic curve at these points intersect in a point which belongs to the curve; reciprocally, he explained how this result could be used to construct a pair of fixed points leading to a construction of a closed quadrilateral.

After having stated all these properties, Steiner added another theorem, whose wording began with a geometric construction presented as similar to that of the previous theorem (see figure 5):

If a curve of the fourth order has two double points $P$ and $Q$, then it is possible likewise to inscribe polygons $A B C D E F \ldots$ in it, whose sides alternatively pass through the fixed points $P$ and $Q$, and the same law occurs:

"If the polygon closes by itself, it always closes and has then the same even number of sides $2 n$, the first point A being chosen at will on the curve." Etc. ${ }^{39}$ [Steiner 1846, p. 184]

The almost exact same wordings of the two theorems, combined with the way Steiner uses the expressions "likewise" and "the same law", attest their affiliation, although such a connection

39"Hat eine Curve vierter Ordnung zwei Doppelpuncte $P$ und $Q$, so lassen sich ihr gleicherweise Polygone $A B C D E F$. . . einschreiben, deren Seiten abwechselnd durch jene festen Puncte $P$ und $Q$ gehen und es findet dasselbe Gesetz statt: ,Dass wenn das Polygon sich schließt, es sich dann immer schließt und dabei stets die nämliche gerade Seitenzahl $2 n$ hat, man mag die erste Ecke A derselben in der Curve annehmen, wo man will. " Etc." 
was not commented by Steiner. Furthermore, the employment of "Etc." at the end of the second theorem seems to allude to the properties of the closed quadrilaterals, hexagons, and decagons that he stated after the first theorem. This locution thus suggests the existence of analogous results in the case of a binodal quartic curve, results that the reader should be able to infer from the cubic case.

A supplementary element reinforces this image of sibling theorems: after having stated the second one, Steiner asserted that "the two theorems [hold] similarly when the sides of the polygon are replaced by conics (instead of straight lines)." 40 More precisely, Steiner explained that this replacement consists first in fixing, in addition to $P$ and $Q$, three other points $X, Y, Z$ on the considered curve, and then in considering the conic passing through $P, X, Y, Z$, and a starting point $A$. His explanations stopped there; let us complete them in the case of a cubic curve. The conic being supposed to intersect the cubic in 6 points, ${ }^{41}$ this yields a point $B$, the sixth intersection point apart from $A, P, X, Y, Z$. Then the conic passing through $B, Q, X, Y, Z$ defines a sixth intersection point $C$, and so on. This produces a polygon $A B C \ldots$ made of an even number of (arcs of) conics which can close by itself or not.

An interesting point is that this completion of Steiner's hints for analogical extension does not adapt to the case of a binodal quartic curve. Indeed, a conic is supposed to intersect such a curve in 8 points, so that a conic passing through $A, X, Y, Z$ (each being counted once), and $P$ (counted twice) intersects the quartic curve in two additional points, and not one. ${ }^{42}$ Whether Steiner here made a mistake or had something else in mind is not clear to me. ${ }^{43} \mathrm{In}$ any case, it is remarkable that Steiner's common, analogical hint to conical extensions, i.e. replacing rectilinear polygons by conical polygons, strengthened the connection of the two theorems.

The first subsequent paper of our corpus dealing with these theorems of Steiner is a paper of Alfred Clebsch published 18 years later, in which the latter used elliptic functions to prove the theorem about cubic curves [Clebsch 1864]. In the mean time, about 20 publications belonging to our corpus appeared, most of them related to the polygons of Poncelet interscribed between two general conics: this is the period of time when Cayley contributed for the most to the corpus, with 9 papers published between 1853 and $1862 .{ }^{44}$

\footnotetext{
40"Die vorstehende Sätze [...] finden analogerweise statt, wenn die Seiten des Polygons Kegelschnitte sind (anstatt Gerade)." [Steiner 1846, p. 184].

${ }^{41}$ Let us recall that, according to the theorem of Bezout, two curves of degrees $n$ and $m$ with no common component intersect in $\mathrm{nm}$ points (counted with multiplicities), under the condition that complex coordinates, as well as points at infinity, are allowed.

${ }^{42}$ This was remarked by Eduard Weyr [1870, p. 26] in a paper devoted to a proof of the theorems about rectilinear polygons for cubics and quartics, and about conical polygons for cubics.

${ }^{43}$ This indecision is notably due to the imprecise formulations used by Steiner. In particular, the significance of the last word of his paper, "Etc.," could either refer to another procedure for the quartic curves, or to additional properties of conical quadrilaterals, hexagons, and octagons, as in the case of rectilinear polygons [Steiner 1846, p. 184].

${ }^{44}$ The corpus contains one more paper of Cayley, which also deals with the polygons of Poncelet, yet from the point of view of $(2,2)$-correspondences, [Cayley 1871b].
} 


\subsection{Cayley and the English porisms}

The result which lies at the core of Cayley's papers is the formulation of necessary and sufficient conditions for the closure of $n$-gons, depending on the numerical coefficients of the equations of the two given conics. To be more precise, Cayley [1853a] proved, with the help of elliptic functions ${ }^{45}$ and invariant theory, that if $U=0$ and $V=0$ are the equations of two conics, and if one expands ${ }^{46}$

$$
\sqrt{\operatorname{det}(U+\xi V)}=A+B \xi+C \xi^{2}+D \xi^{3}+E \xi^{4}+F \xi^{5}+\cdots,
$$

then there exist Poncelet's triangles, quadrilaterals, pentagons, hexagons, heptagons, etc., if and only if

$$
C=0, \quad D=0, \quad\left|\begin{array}{ll}
C & D \\
D & E
\end{array}\right|=0, \quad\left|\begin{array}{ll}
D & E \\
E & F
\end{array}\right|=0, \quad\left|\begin{array}{lll}
C & D & E \\
D & E & F \\
E & F & G
\end{array}\right|=0, \text { etc. }
$$

Cayley also specified these conditions under given particular conditions: for example, he considered the special case of two conics defined by the equations $U=y^{2}-4 x z=0$ and $V=a x^{2}+b y^{2}+c z^{2}=0$, and, computing the corresponding coefficient $C$, proved the condition of existence of interscribed triangles to be $a c+16 b^{2}=0$ [Cayley 1857]. In [Cayley 1861], Cayley also computed the conditional determinants up to $n=9$ in function of the coefficients $\beta, \gamma, \delta$ defined by $\operatorname{det}(U+\xi V)=1+4 \beta \xi+4 \gamma \xi^{2}+4 \delta \xi^{3}$. In another publication, [Cayley 1853b], he considered the case of two given circles, and proved that his formulas matched those already known, as the one for triangles $a^{2}=R^{2}-2 r R$, mentioned above.

An interesting feature of Cayley's works is his use of the word "porism" to refer to the theorem about the interscribed polygons. For instance, the titles of almost all his publications in the corpus mention "the porism of the in-and-circumscribed polygon," or "the porism of the in-and-circumscribed triangle." More generally, the use of this word within Cayley's published research is almost exclusively linked with the interscribed polygons: a textual search in his Collected Mathematical Papers reveals that "porism" is employed only in the texts of our corpus, plus a paper of 1871 where it is used in the context of the polygons of Poncelet and the chains of circles of Steiner [Cayley 1871a]. ${ }^{47}$

This 1871 paper is interesting for the question of the use of the word "porism," because it clearly makes a distinction between "porism" and "problem." Indeed, one of the questions tackled by Cayley in this paper was to "connect together the porisms arising out of the two problems":

\footnotetext{
${ }^{45}$ As is remarked in [Del Centina 2016, p. 54], Cayley explicitly placed his works as a continuation of Jacobi [1828]: "The preceding investigations were, it is hardly necessary to remark, suggested by a well-known memoir of the late illustrious Jacobi, and contain, I think, the extension which he remarks it would be interesting to make of the principles in such memoir to a system of two conics." [Cayley 1853c, p. 284].

${ }^{46}$ Since $U$ and $V$ are both quadratic forms in three variables, they are associated with symmetric matrices with three rows and three columns. The determinant $\operatorname{det}(U+\xi V)$ of the formula refers to the determinant of the matrix obtained from these two ones, the letter $\xi$ denoting a complex variable.

${ }^{47}$ Let us add that "porism" also appears in a biographical notice that had been inserted in the 8th volume of the Papers after his death [Cayley 1895, pp. ix-lxiv]. This appearance is also linked with the polygons of Poncelet (see p. xlii).
} 
(1) given two conics, to find a polygon of $n$ sides inscribed in the one and circumscribed about the other.

(2) given two circles, to find a closed series of $n$ circles each touching the two given circles and the two adjacent circles of the series. [Cayley 1871a, p. 202]

A few lines later, Cayley stated the first of the mentioned porism:

The porism in regard to the two conics is, that in general it is not possible to find any polygon of $n$ sides satisfying the conditions; but that the conics may be such that there exists an infinity of polygons; viz. any point whatever of the one conic may then be taken as a vertex of the polygon, and then constructing the figure, the $(n+1)^{\text {th }}$ vertex will coincide with the first vertex, and there will be a polygon of $n$ sides. [Cayley 1871a, p. 203]

Thus the word "porism" was clearly used to refer to the formulation of the proposition linked to the corresponding problem, a formulation consisting in an alternative between a situation where no solution exists, and another one where infinitely many solutions exist.

This can be confirmed at other places in our corpus, sometimes through the use of the adjective "porismatic." Indeed, Cayley explained (in the context of polygons interscribed between two conics) that "the porismatic property is that, if for a given position of [a point] $A$ this series closes at a certain term, [...] then it will always close, whatever be the position of $A$ " [Cayley 1871b, p. 84]. Besides, many other British mathematicians also used the terms "porism" and "porismatic" in their contributions to our corpus. For example, Andrew Hart talked about "the porism of the in-and-circumscribed triangle" [Hart 1858], Henry Martyn Taylor dealt with "the porism of the ring of circles touching two circles" [Taylor 1878], and Joseph Wolstenholme, in a paper devoted to a particular case of the interscribed polygons, even applied the adjective "porismatic" to qualify a system of equations having "either no solutions or an infinite number" [Wolstenholme 1870, p. 356].

The term "porism" comes from the title of a lost book of geometry of Euclid, known through a notice of Pappus and some comments of Proclus. ${ }^{48}$ Both Pappus and Proclus had tried to account for the meaning of the word "porism," but their explanations were quite obscure. As Thomas Heath explained, for Proclus, a porism was a kind of proposition situated somewhere between a problem and a theorem: "it deals with something already existing, as a theorem does, but has to find it (e.g. the center of a circle), and, it partakes to that extent of the nature of a problem, which requires us to construct or produce something not previously existing" [Heath 1921, p. 434]. The questions of restoring the content of Euclid's Porisms and interpreting the meaning of its title have been attempted since the seventeenth century by mathematicians like Albert Girard, Pierre Fermat, Robert Simson, John Playfair, and Michel Chasles.

According to Heath [1911, p. 103], it is Playfair's definition that has been "most favoured in England [while] Simson's view has been most generally accepted abroad, and has the support of the great authority of Michel Chasles." For Playfair, a porism was "a proposition affirming the possibility of finding such conditions as will render a certain problem indeterminate, or capable of innumerable solutions" [Playfair 1794, p. 170], a definition which strongly echoes

\footnotetext{
${ }^{48}$ See [Heath 1921, vol. 1, pp. 431-438]. Let us recall that Thomas Heath (1861-1940) was a English civil servant and a historian of mathematics, specialized in the Greek Antiquity. For an overview on his historical works, see [Wardhaugh 2016].
} 
our previous remarks on Cayley, Hart, Taylor, etc. On the contrary, Simson's definition of a porism does not strikingly match these remarks, as it explains that a porism is "a proposition in which it is proposed to show that something or several things are given when it is required that a certain common property described in the proposition is satisfied by it or by them as well as by one of innumerable things which are not in fact given but which have the same relation to those things that are given." 49

Maybe because of the distance between the latter definition and the formulations of the theorems on the polygons of Poncelet and on the chains of Steiner, and because it was the one which was commonly accepted in the continental part of Europe, I found only two non-English texts in the corpus where the word "porism" appears. The first one is [Steiner 1826] which we already presented, but, as "porims" is only employed twice in the general statements introducing this paper, it is difficult to understand what it points to. The second one is [Poncelet 1862], where Poncelet commented the works of Cayley related to the interscribed polygons and reproached him for not having cited the Traité:

Monsieur Cayley [...], being certainly unaware of my publications [...], gratuitously attributed to [Fuss], under the denomination of porism, the theorem [on polygons interscribed between two circles]..$^{50}$ [Poncelet 1862, p. 483]

Interestingly, this extract displays a certain distance (maybe a distaste?) between Poncelet and the use of the word "porism," a distance which could reflect a difference between the French and the English appreciation of this word. Indeed, the French "porismes" and the German "Porismen" were actually used at the time of Cayley, but in the context of Euclid's book (see for instance [Cantor 1857; Chasles 1860]). Thus it is possible that in these languages, "porism" was mainly, if not exclusively, employed in such a context, or that it lost its ancient meaning at some point. ${ }^{51}$

This English specificity is of particular interest for our question of the constitution of the category of closure theorems because Cayley's and the other English contributors' use of "porism" indicates that they did acknowledge a distinct form of the theorems of Poncelet and of Steiner, but that this form was recognized to be a case of the already-existing category of porisms. As we will see, the German label Schliessungssätze and its variants seem, on the contrary, to have been created from the examples of Poncelet and Steiner, which displays another kind of mechanism: the constitution of a new, proper category of problems and theorems. Finally, it is striking that no encompassing words have been employed at all by French authors. For example, Poncelet's theorem was often called "le (célèbre) théorème de Poncelet," sometimes "le théorème de fermeture de Poncelet," but there were no occurrence of phrases like "les théorèmes de clôture." In this sense, the French contributors of our corpus did not directly participate to the constitution of an explicit category of closure theorems. But their papers, which were read by the other mathematicians, did connect together some of the theorems of closure: by analogy, as observed above, but also by technical links, as

\footnotetext{
${ }^{49}$ This definition is included in a work (written in Latin) of Simson published after his death, in 1776. The present English translation comes from [Tweddle 2000, p. 17].

50"M. Cayley, qui, ignorant sans doute mes publications [...], a attribué gratuitement à [Fuss], sous le nom de porisme, le théorème de la page 364 sur les cercles [...]."

${ }^{51}$ For instance, the French Encyclopédie explains that a "Porisme (Géom.) est la même chose qu'un lemme, qui est aujourd'hui seul usité." This definition dates from 1765. See the new online edition of the Enyclopédie, ENCCRE: http: //enccre.academie-sciences. fr (seen on November 4 2017).
} 
exemplified in what follows now. ${ }^{52}$

\subsection{The theorem of Poncelet as an element of proof}

Before ending this section, we thus mention two papers in which technical links between two different geometrical situations emerged. The first one was published by Paul Serret in 1862, and aimed at presenting new demonstrations of the theorems on the chains of circles and of spheres. Let us look for instance at the proof of the theorem of the chains of circles, consisting in "reducing this theorem to that of Monsieur Poncelet." 53 For this purpose, Serret proved two lemmas. The first one is that the locus of the centers of circles that are tangent to two fixed circles is a conic; the second one is that if a chain of circles is given, then the points of contact of the circles of the chain lie on a circle (see figure 6). Then the polygon whose vertices are the centers of the circles making a chain is inscribed in the conic of the first lemma and circumscribed about the circle of the second one: this allowed Serret to deduce the theorem about the chains of circles thanks to the theorem of Poncelet.

Serret thus established a direct mathematical link between the two situations of the chains of circles and the polygons of Poncelet, which were not presented a priori as extensions of one another, contrary to the case of Durrande's proof of the theorem on tetrahedrons and spheres for instance.

Two years later, Théodore Moutard published a short article in Nouvelles Annales de mathématiques devoted to the study of a particular kind of surfaces called "anallagmatic surfaces of the fourth order" [Moutard 1864b]. ${ }^{54}$ At the very end of it, Moutard deduced from his study of anallagmatic quartic surfaces a theorem which is "independent of the anallagmatics, and entirely analogous to the famous theorem of Monsieur Poncelet about the polygons simultaneously inscribed and circumscribed to two conics":

It is in general impossible to inscribe in the intersection curve of a hyperboloid and another surface of the second order a polygon having a given even number of sides and

\footnotetext{
${ }^{52} \mathrm{~A}$ current echo of this curious trichotomy can be observed in the Wikipedia pages devoted to the theorem of Poncelet: while the French one is called "Grand théorème de Poncelet," the English one is about "Poncelet's porism (sometimes referred to as Poncelet's closure theorem)," and the German one is entitled "Schliessungssatz von Poncelet" (seen on November 4 2017). It would be premature, at this stage of the study, to infer general conclusions on larger national divergences, for instance about inclinations to forge neologisms, or about preferences in the way of classifying in mathematics.

53“'On peut, à l'aide des lemmes suivants, ramener ce théorème à celui de M. Poncelet.” [Serret 1862, p. 184]. Serret offered a second proof, in which the two fixed circles are transformed into two concentric circles by means of an inversion. Let us recall that the inversion of center $\Omega$ and of parameter $k$ is the transformation which associates, to a point $M$, the point $M^{\prime} \in(\Omega M)$ such that $\overline{\Omega M^{\prime}} \cdot \overline{\Omega M}=k$.

${ }^{54} \mathrm{~A}$ surface of the fourth order, also called a quartic surface, is a surface that can be defined by a polynomial equation of degree 4. A surface (of the fourth order or not) is said to be anallagmatic if there exists an inversion which leaves it invariant. The notion of anallagmatic surface was defined by Moutard himself in an article published in the same volume of Nouvelles Annales de mathématiques as the one we are describing here [Moutard 1864a]. About anallagmatic surfaces, in particular as tackled by Gaston Darboux, see [Croizat 2016, ch. 2]. Moreover, another text of Moutard belongs to the corpus, [Moutard 1862], which is a supplement to Poncelet's book Applications d'analyse et de géométrie, qui ont servi de principal fondement au Traité des propriétés projectives des figures [Poncelet 1862]. The supplement was entirely devoted to the polygons of Poncelet; in particular, Moutard used elliptic functions to find conditions expressing the possibility of existence of $n$-gons interscribed between two conics, yet in a different way than Cayley did.
} 


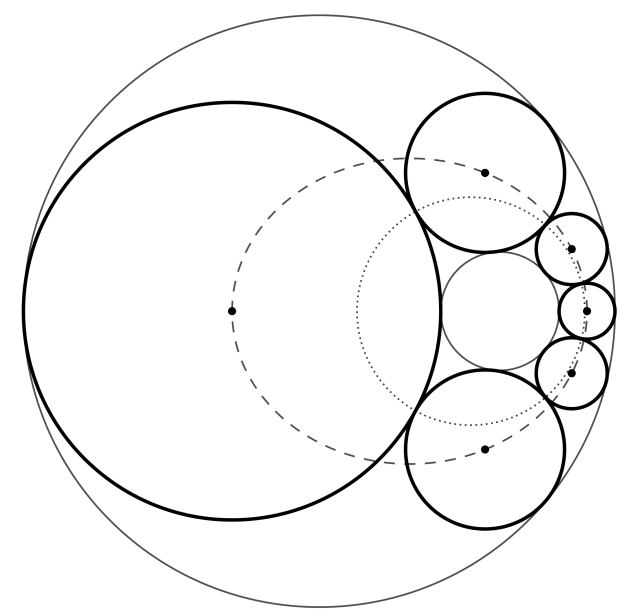

Figure 6 - The centers of any chain of circles associated to the two fixed ones describe an ellipse (the dashed line), and the points of contact describe a circle (the dotted line).

made of rectilinear generators of the hyperboloid; 55 but if it is possible to find one such polygon, then there exist infinitely many others.

Moutard then concluded his paper alluding to the fact that "this theorem can be deduced from that of Monsieur Poncelet by a mere perspective." 56

Hence the link presented by Moutard between his theorem and that of Poncelet was double. On the one hand, the former was presented as "analogous" to the latter, an analogy which, in the absence of any further explanation, seems to refer to the formulation of the theorem according to which the existence of one polygon implies the existence of an infinity of polygons. On the other hand, Moutard hinted to a technical link consisting in a geometric transformation (a perspective) allowing one to pass from the theorem of Poncelet to the theorem of Moutard, and incidentally yielding another way to prove the latter.

From prehistorical works on the polygons of Poncelet to this research of Moutard, the different geometric problems and theorems dealt with in the corpus gave rise to research full of diverse extensions and analogies, which, however, were never commented on by their authors. In particular, this research did not bring any explicit grouping of theorems to light. Links between different theorems seemed to be only grounded on similar wordings, even if a few technical links were proved at the beginning of the 1860s. Thus, the unity of the theorems that we have encountered until now, and that would later be recognized as instances

\footnotetext{
${ }^{55}$ Let us recall that a hyperboloid is a special kind of quadric surface which contains infinitely many straight lines called the (rectilinear) generators of the surface. More precisely, through each point of the surface pass exactly two generators: this yields two families of lines which both describe the surface.

56"On rencontre ainsi un théorème indépendant des anallagmatiques, tout à fait analogue au célèbre théorème de M. Poncelet sur les polygones simultanément inscrits et circonscrits à deux coniques : dans la courbe d'intersection d'un hyperboloïde et d'une autre surface du deuxième ordre, il est, en général, impossible d'inscrire un polygone d'un nombre pair donné de côtés formé par des génératrices rectilignes de l'hyperboloïde; mais lorsqu'on pourra en trouver un, il en existera une infinité d'autres. Ce théorème se déduit de celui de $\mathrm{M}$. Poncelet par une simple perspective." [Moutard 1864b, p. 539].
} 
of the theorems of closure, was mostly assured by resemblances of formulations and of associated questions (like the search for metric relations). The situation would change from the mid-1860s on, as mentions of some classes of theorems began to occur in the corpus.

\section{From a class of problems to the problems of closure}

\subsection{Hints to certain classes of problems}

As explained earlier, in 1864 Clebsch published a paper in which he aimed to prove the theorem on polygons inscribed in cubic curves that Steiner had stated in 1846 [Clebsch 1864]. In the introduction of the paper, after having recalled this theorem, Clebsch evoked the name of Jacobi, who he associated with the theory of elliptic functions:

The nature of the mentioned theorem immediately leads to the assumption that we have here an instance of the class of algebraic problems about which Jacobi showed how easily they can be connected with the theory of elliptic functions. ${ }^{57}$ [Clebsch 1864 , p. 94]

Clebsch did not make explicit which works of Jacobi he had in mind, but it is very likely that it was the 1828 paper where Jacobi tackled the problem of Poncelet's polygons with elliptic functions. ${ }^{58}$

Two other elements of the previous quotation are more difficult to interpret. First, the meaning of the "nature" of the theorem of Steiner is not clear: it could refer to several of its characteristics, like the objects that are involved in it (polygons and algebraic curves of small degree), the fact that it pertains to the closure of an iterative geometric construction, its formulation as an alternative (of the non-existence of closed polygons or the existence of infinitely many of them), or even to a combination of these three features. Secondly, it may seem odd that Clebsch talked about "algebraic" problems, and not geometric ones. An explanation could be that he aimed at problems that would be geometrically disembodied and that would underlie the theorems of Poncelet and of Steiner, like the problem of the division of elliptic functions. ${ }^{59} \mathrm{In}$ any case, it is remarkable that Clebsch acknowledged the existence of a class of problems, the belonging to which was characterized by the recognition of a resemblance of nature.

Moreover, the affiliation thus expressed between the theorems of Poncelet and of Steiner was accompanied by a transfer of method: because the theorem of Steiner looked like that of Poncelet, the theory of elliptic functions, which had been successfully used to prove the latter, would also help prove the former. This transfer, however, only consisted in the general idea of introducing elliptic functions; the technical steps of Clebsch radically differed from those of Jacobi. In particular, Clebsch used invariant theory in combination with elliptic functions in order to parameterize the points of any (non singular) cubic curve with these functions.

\footnotetext{
57“'Die Natur des angeführten Satzes führt sofort zu der Vermuthung, dass man hier eines aus der Classe jener algebraischen Probleme vor sich habe, welche Jacobi mit der Theorie der elliptischen Functionen in so einfachen Zusammenhang bringen gelehrt hat."

${ }^{58}$ As depicted by the authors of his obituary [Brill et al. 1873, p. 7], Clebsch had not personally known Jacobi, but he had studied his works a great deal and used to present himself as one of his students.

${ }^{59}$ This problem of division does appear later in Clebsch's paper. See [Lê 2018], where this research of Clebsch is studied in depth.
} 
The key point, then, was that three points of the curve of parameters $u_{1}, u_{2}, u_{3}$ are aligned if and only if $u_{1}+u_{2}+u_{3}$ is congruent to a constant modulo an integral combination of the periods of the elliptic function sn.

The idea of a certain class of problems linked to that of Poncelet's polygons also appeared in some research that Jacob Rosanes (1842-1922) and Moritz Pasch (1843-1930) did during the second half of the 1860s. ${ }^{60}$ In 1865 , they published an article where they explained that they wanted to find conditions on the coefficients of two conics expressing the possibility of existence of interscribed polygons [Rosanes and Pasch 1865]. They began by citing the works of Steiner relative to particular cases of polygons interscribed between two circles, as well as those of Jacobi, who managed, "in a surprising way, to establish the conditions for any polygon with the help of elliptic functions."61 Rosanes and Pasch also explained that Cayley's [1853a,b] and Moutard's [1862] works on the same question had been unknown to them until shortly before the publication of their paper, but they added that both the "route taken" and the "form of the results" differed from Cayley's and Moutard's approaches. ${ }^{62}$

A few years later, Rosanes and Pasch published another joint paper, which they linked to the previous one, explaining that the problem they had tackled there was the source of an algebraic problem they wanted to study now [Rosanes and Pasch 1869]. Actually, not only did they refer to the polygons of Poncelet, but they also evoked a certain "class of such problems":

The geometric problem treated in this journal [Rosanes and Pasch 1865] — and even a class of such problems - appears, when interpreted purely algebraically, in the following form. ${ }^{63}$ [Rosanes and Pasch 1869, p. 169]

Furthermore, the same idea was also contained in the title of the paper: "On an algebraic problem underlying a type of geometric problems." 64 The extent and the content of the evoked class of geometric problems were not discussed by Rosanes and Pasch, but the explanations on the algebraic one gives us clues which illuminate the question.

Indeed, this algebraic (form of the) problem was presented by Rosanes and Pasch as follows. They defined a function

$$
F(x, y)=a x^{2} y^{2}+2 b x y(x+y)+c(x+y)^{2}+2 d x y+2 e(x+y)+f,
$$

and considered a sequence of numbers $t_{0}, t_{1}, t_{2}, \ldots$ such that $F\left(t_{0}, t_{1}\right)=0, F\left(t_{1}, t_{2}\right)=0$,

\footnotetext{
${ }^{60}$ Rosanes and Pasch were friends, had both studied at the University of Breslau, and had both defended their doctoral thesis (made under the supervision of Heinrich Schröter) in 1865. The research we describe here is among the very first of Rosanes and Pasch. See Pasch's autobiography [Pasch 1930]. Pasch is now better-known for his works on the foundations of geometry, see [Gandon 2005].

61"Jacobi [...] gelang es, für die Voraussetzung, dass ein Kreis den anderen ganz umschliesst, die Bedingung für ein beliebiges Polygon auf überraschende Weise mit Hülfe der elliptischen Functionen aufzustellen.” [Rosanes and Pasch 1865, p. 126].

62"Die gegenwärtige Abhandlung, deren Verfasser von den letztgenannten beiden Arbeiten bis vor kurzer Zeit keine Kenntniss hatten, scheint von diesen sowohl in Bezug auf den eingeschlagen Weg, als die Form der Resultate, welche grosse Aehnlichkeit mit den von Jacobi gefundenen Formeln aufweist, sosehr verschieden, dass die Veröffentlichung derselben wohl gerechtfertigt erscheinen dürfte.” [Rosanes and Pasch 1865, p. 126].

${ }^{63}$ "Die in diesem Journal Bd. 64 S. 126 ff. behandelte geometrische Aufgabe — und überhaupt eine Klasse von solchen — tritt, rein algebraisch aufgefasst, in foldender Form auf."

64"Ueber eine algebraische Aufgabe, welche einer Gattung geometrischer Probleme zu Grunde liegt."
} 
$F\left(t_{2}, t_{3}\right)=0$, etc. ${ }^{65}$ Their problem, then, was to find conditions on the coefficients of $F$ implying that $t_{n}=t_{0}$ and $t_{n+1}=t_{1}$ for some integer $n>2$, which in turn implies that $t_{k}=t_{n+k}=t_{n-k}$ for every integer $k$. In Rosanes and Pasch's own words, it was thus demanded to find conditions on $a, b, \ldots, f$ so that the sequence $t_{0}, \ldots, t_{n}$ "closes by itself." ${ }^{66}$ Later in the text, they specified that "the sequence $t_{0}, t_{1}, t_{2}, \ldots$ either does not close at all, or closes for every value of $t_{0},{ }^{\prime}{ }^{67}$ a property whose formulation, consisting in an alternative of the non-existence of closing sequences or the existence of infinitely many, clearly echoes those of the different theorems that we described above. Therefore it is very probable that these problems were the ones which were encompassed in the "class" they had in mind. ${ }^{68}$

Clebsch, Rosanes, and Pasch thus explicitly recognized the existence of classes of problems linked with the polygons of Poncelet or those of Steiner. Even if the actual content of these classes was not explicitly delineated, it seemed to be associated to the particular formulations of the problems or to their nature. This marks a particular step in the process of categorization of the problems and theorems of closure. Another one would be to distinguish them with the creation and the use of a specific label.

\subsection{A new label}

Eduard Weyr (1852-1903) wrote a paper in 1870 in which he aimed at proving the theorems that Steiner had stated in 1846 about the polygons inscribed in cubics and in binodal quartics [Eduard Weyr 1870]. ${ }^{69}$ Weyr explained that even if the theorem about cubic curves had been proved by Clebsch with elliptic functions in 1864, he sought for demonstrations that would not involve these functions. Thus, after having quoted Steiner's two theorems, he wrote:

Although the connection of the first of these two Schliessungsprobleme with the theory of elliptic functions has already been presented by Herr Clebsch [1864], it is still interesting to prove the two theorems of Steiner [...] independently from any consideration of transcendent functions, and to fathom their relation with certain elementary geometric

\footnotetext{
${ }^{65}$ The first term $t_{0}$ being chosen at will, there are two choices for $t_{1}$, namely the two solutions of the quadratic equation $F\left(t_{0}, y\right)=0$. After having chosen $t_{1}$, one considers the equation $F\left(t_{1}, y\right)=0$ : because of the symmetry of $F$, the first term $t_{0}$ is a solution. The term $t_{2}$ is thus uniquely determined, as the other solution; equivalently, $t_{2}$ is the solution of the equation $F\left(t_{1}, y\right) /\left(y-t_{0}\right)=0$. For the same reasons, all the terms $t_{k}$ with $k>2$ are then completely determined.

${ }_{66}$ "[D]ie Werthe $t_{0}, \ldots, t_{n}$ sollen eine Reihe bilden, welche sich von jedem aus nach beiden Seiten schliesst." [Rosanes and Pasch 1869, p. 169].

${ }^{67}$ "Die Reihe $t_{0}, t_{1}, t_{2}, \ldots$ schliesst sich also entweder gar nicht oder für jeden Werth von $t_{0}$." [Rosanes and Pasch 1869, p. 172].

${ }^{68}$ After having solved the algebraic problem, Rosanes and Pasch applied it to that of the polygons of Poncelet, but this was the only application.

${ }^{69}$ This paper was written while Eduard Weyr was still a student both at the Technical University and at the Charles-Ferdinand University in Prague. Later, in 1872, he completed his mathematical training in Göttingen, where he attended lectures of Clebsch, met Felix Klein, and obtained his doctorate (about spatial algebraic curves) in 1873. After a year spent in Paris, he returned to Prague in 1874 where he obtained his Habilitaion. According to the Jahrbuch, almost all of Weyr's first reviewed publications (1869-1875) pertain to algebraic curves and surfaces. Later, Weyr also contributed to algebraic topics: about his works on the decomposition of matrices, see [Brechenmacher 2010, p. 579 sqq.]. Note that Eduard Weyr had a brother, Emil Weyr (1848-1894), who was also a mathematician, and who also contributed to the subject of the theorems of closure. For the people with the ability to read the Czech language (which is not the case for me), see [Bečvár 1995].
} 
figures..$^{70}$ [Eduard Weyr 1870, pp. 18-19]

This excerpt displays the first appearance of the word Schliessungsprobleme in our corpus. If it would later reappear in a singular form (like in the phrase: "the Schliessungsproblem of Poncelet"), let us note that Weyr used it here in a plural version meant to gather two entities under a common label. This label, of course, explicitly refers to the question of the closure of the diverse polygons associated to given curves, and the very act of labeling clears up some of the ambiguities related to the content of Clebsch's, and of Rosanes and Pasch's vague "classes."

As announced in our introduction, the label Schliessungsprobleme and its variants became commonly used in the corpus Weyr's 1870 text. Moreover, even if this label can hardly be seen as a very inventive new one-this neologism is a mere reunion of the common words Schliessung and Probleme-, its specificity and its uses at many places indicates that it was collectively adopted to designate a recognized, specific category of problems and theorems. But such uses would often be accompanied by other elements that would (explicitly or implicitly) strengthen the constitution of this category. Here, the problems of closure that Weyr wanted to prove were connected together by their very inclusion in the set of Schliessungsprobleme, but also by a will to exclude elliptic functions from their proofs and by technical features that incidentally appeared.

Indeed, Weyr grounded his approach on the notion of " $(2,2)$-correlated fundamental figures of the first degree." 71 Essentially, figures of the first degree are families of geometric objects that can be described by one parameter, as the points on a line or the lines (on a plane) passing through a fixed point. Two such families are said to be $(2,2)$-correlated if there is a way to associate, to each element of one family, two elements of the other one, and reciprocally. Weyr considered for instance a cubic curve with two points $P$ and $Q$ on it: these points define two families of lines, and one declares that two lines of these families are correlated if they meet on the curve. Since a line passing through $P$ intersects the curve in two additional points, this is a $(2,2)$-correlation (see figure 7 ).

Weyr also explained how two families of lines (passing through fixed points) that are $(2,2)$-correlated can be used to define binodal quartic curves and cubic curves. The rough idea is that if two such families are given, then the locus of the points of intersection of corresponding lines is, in general, a quartic curve; bidonal quartics and cubics arise as particular cases of this construction.

The key point of the article is a theorem about $(2,2)$-correlated figures of the first degree, ${ }^{72}$ a theorem "to which the theorems of Steiner will be reduced":

Let us consider two fundamental figures $S$ and $\Sigma$ [of the first degree] that are $(2,2)$ correlated, and suppose that there exist two groups of $n$ elements $(a, b, c \ldots$ on $S$, and

\footnotetext{
70"Obgleich das erste dieser beiden Schliessungsprobleme bereits in seinem Zusammenhange mit der Theorie der elliptischen Functionen von Herrn Clebsch (Bd. 63, pag. 94 dieses Journal) dargestellt worden ist, so bleibt es doch von Interesse, die obigen Steinerschen Sätze [...] unabhängig von der Betrachtung transcendenter Functionen zu beweisen und ihren Zusammenhang mit den Beziehungen gewisser geometrischer Elementargebilde zu ergründen."

71 "Zwei und zweigliedrig verwandten Grundgebilde ersten Grades". We will see that other mathematicians talked about "(2, 2)-Korrespondenzen."

${ }^{72}$ The proof of this theorem contained a mistake and was corrected in the subsequent paper [Eduard Weyr 1871]. The fact that the correction implied differential calculus would later be remarked by other mathematicians, who qualified Weyr's approach of the theorems of Steiner as non-"geometric."
} 


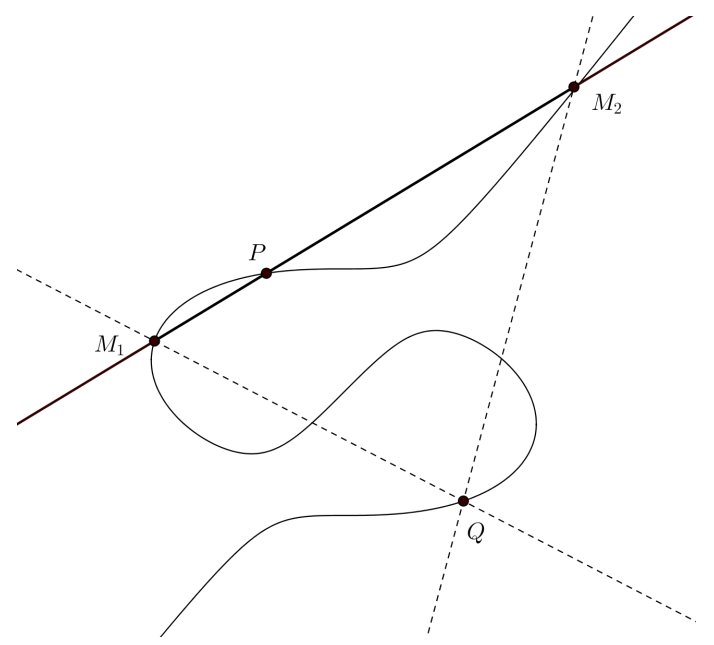

Figure 7 - The line $\left(M_{1} M_{2}\right)$ is correlated with the lines $\left(Q M_{1}\right)$ and $\left(Q M_{2}\right)$ because their respective intersection points lie on the cubic curve.

$\alpha, \beta, \gamma \ldots$ on $\Sigma$ ) such that the two elements corresponding to any element of one group belong to the other group. Then there exist infinitely many such associated groups; namely, every element of the fundamental figures belongs to one such group. Such groups cannot have more or less than $n$ elements. $^{73}$ [Eduard Weyr 1870, p. 22]

Interestingly, when Weyr applied this theorem in order to prove the theorems of Steiner, he remarked that, as two families of lines could generate both a binodal quartic curve and a cubic curve, he just had to consider "the generated curve," without specifying its order. This allowed him to prove the two theorems of Steiner at the same time. ${ }^{74}$

Finally, after having proved them, Weyr indicated that his demonstration had led him to "a theorem which is analogous to those of Steiner, and which is related to the intersection curve of two ruled surfaces of the second order." 75 To be more precise, related to polygons made of generators of two ruled surfaces of the second order and inscribed in the spatial quartic curve defined as the intersection of these surfaces. ${ }^{76}$ Weyr formulated it as follows:

If two ruled pencils of the second order $S$ and $\Sigma$ have a space curve $C_{4}$ in common, ${ }^{77}$ let us draw the line belonging to $S$ going through a point $A$ of this curve until it cuts $C_{4}$

73"Wir sprechen folgenden Satz aus, auf welchen sich die Steinerschen Sätze zurückführen lassen werden: Sind zwei einförmige Grundgebilde $S$ und $\Sigma$ zwei und zweigliedrig auf einander bezogen, und kann man in jedem derselben eine Gruppe von $n$ Elementen $a, b, c \ldots$ resp. $\alpha, \beta, \gamma \ldots$ so angeben, dass sich die einem beliebigen Elemente der einen Gruppe zugeordneten zwei Elemente in der anderen Gruppe befinden, so existiren unendlich viele solcher beigeordneten Gruppen, nämlich jedes Element ist in einer solchen Gruppe enthalten. Gruppen dieser Art von mehr oder weniger als $n$ Elemente giebt es nicht."

${ }^{74}$ The link with the previously quoted theorem is that a closed polygon gives rise to two groups $S$ and $\Sigma$, respectively made of the sides passing through $P$ and through $Q$.

75"Es möge zum Schlusse als eine weitere Folgerung des gegebenen Beweises ein den Steinerschen Sätzen analoger Satz für die Schnittcurve zweier Regelflächen zweiter Ordnung aufgestellt werden."

${ }^{76} \mathrm{~A}$ ruled surface is a surface containing infinitely many lines. As we saw above, hyperboloids are examples of ruled surfaces of the second order. More generally, when considered as surfaces in the complex projective space, all the surfaces of the second order are ruled surfaces: through each point of such a (smooth) surface pass two lines. It is thus possible to describe a ruled quadric surface thanks to two different families of lines, just as in the specific case of hyperboloids.

${ }^{77}$ The fact that Weyrs here talks about "ruled pencils of the second order" means that $S$ and $\Sigma$ are both seen as 
a second time in $B$, then draw the line belonging to $\Sigma$ going through $B$ until it meets $C_{4}$ once more in $C$, and further draw the line belonging to $S$ going through $C$, which will have another point $D$ in common with $C_{4}$, etc., so that we obtain a skew polygon $A B C D$. . ; this polygon either does not close itself, how long one may carry on the construction, or closes itself, and has then an even number $2 n$ of sides. In this case, it always closes itself and has each time the same number of sides $2 n$, wherever the starting point $A$ is chosen on $C_{4}{ }^{78}$ [Eduard Weyr 1870, p. 28]

The proof consisted in defining a $(2,2)$-correlation between the lines composing $S$ and those composing $\Sigma$, and then in applying once more the previous theorem.

The analogy between this theorem and those of Steiner was made manifest by the choice of the wording of the former, which looked just like those of the latter, and thus was reinforced in the technical details by a proof based on the same general theorem. This new theorem about polygons inscribed in spatial quartic curves was certainly qualified as a theorem of closure, even if Weyr did not label it as such. But this would be done by other mathematicians in research papers published a few years later, and eventually in the corresponding chapter of the Encyklopädie, [Staude 1904].

\section{Searching for common sources of the theorems of closure}

During the five years following the paper of Weyr [1870], a dozen texts of the corpus were published. Let us only mention here one of them which would be frequently cited in subsequent works, namely the monograph of Gaston Darboux devoted to the surfaces called cyclides, [Darboux 1873]. As has already been noted, this monograph contained a new proof of the theorem of Poncelet, as well as some generalizations of this theorem; Darboux also proved how this theorem was connected to that of Moutard [1864a] about polygons inscribed in a spatial quartic curve. ${ }^{79}$

We now turn to three articles (two of them published in 1876, the third one in 1879) which appear as singularities within the corpus because they are the only ones whose authors not only explicitly gathered a number of theorems under the label "closure theorems," but also presented technical reasons to explain the unity of this category of theorems. It is remarkable that each author connected his approach to a particular domain of mathematics: geometry for the first one, the theory of elliptic functions for the second one, and algebra for the third one.

quadric surfaces generated by one family of lines (among the two possible ones). Thus, through each point of $S$ (resp. $\Sigma$ ) passes only one line belonging to $S$ (resp. $\Sigma$ ).

78"Haben zwei Regelschaaren zweiter Ordnung $S$ und $\Sigma$ eine Raumcurve $C_{4}$ gemein, und man zieht durch einen Punkt $A$ derselben den zu $S$ gehörigen Strahl, bis er $C_{4}$ zum zweiten Male in $B$ schneidet, ferner durch $B$ den $\Sigma$ gehörigen Strahl, bis er $C_{4}$ noch einmal in $C$ trifft, weiter durch $C$ den in $S$ liegenden Strahl, der mit $C_{4}$ überdies einen Punkt $D$ gemein haben mag u.s.w., so erhält ein windschiefes Polygon $A B C D \ldots$; dieses Polygon schliesst sich entweder nicht, wie weit man auch dieses Verfahren fortsetzen mag, oder es schliesst sich und hat dann eine gerade Seitenzahl $2 n$. In diesem Falle schliesst es sich immer und hat jedesmal die nämliche Seitenzahl $2 n$, wo man den Anfangspunkt A auf $C_{4}$ auch annehmen mag."

79"Cette première proposition, comme Monsieur Moutard en a fait le premier la remarque en 1864 [...], est au fond le théorème de Poncelet; elle s'est déduit par une simple perspective." About Darboux's monograph, see [Del Centina 2016, pp. 91-102; Croizat 2016, pp. 318-340]. 


\subsection{The simplest possible geometric considerations}

The first one is an article of Friedrich August (1840-1900), published in the 1876 volume of Archiv der Mathematik und Physik, and entitled "On the connection between certain theorems referring to closed series of geometric figures" [August 1876b]. ${ }^{80}$ August evoked at once the existence of a certain family of theorems, as he listed a number of examples of "the kind of theorems which are dealt with in [his] research." 81 The list began with cases of the theorem of Poncelet, first stated for triangles and concentric circles, then for triangles and any circles, for polygons and circles, and finally for polygons and conics. August then recalled that Steiner had given other "similar theorems" about closed chains of circles and spheres, as well as theorems on polygons and cubic curves, which "belong to the same type." 82 This enumeration of theorems served August to emphasize their coherence and therefore to justify the search for mathematical reasons linking them together:

The great consistency of these theorems makes us guess that they can be explained from a common point of view, and indeed the analytic treatment revealed that both the theorems of Poncelet and those about the polygons of Steiner led to the theorem of addition of the elliptic integrals of the first kind, as proved by Jacobi and Clebsch.

Although the connection between these theorems has thus been discovered, it remains desirable to explain this connection in a geometric way, and so to find a theorem from which the above-mentioned theorems can be deduced, by means of the simplest possible geometric considerations. ${ }^{83}$ [August 1876b, p. 2]

August thus acknowledged that elliptic functions provided a point of view explaining the listed theorems as a whole, but he wanted to exclude these transcendent functions and to find a "geometric" alternative.

As the list of the theorems given in the previous quote reveals, August sought for a common view on Poncelet's polygons, on Steiner's polygons, and on Steiner's chains of circles. Yet August also made an inventory of "other closure theorems of less elementary

80"Ueber den Zusammenhang gewisser Sätze, welche sich auf geschlossene Reihe geometrischer Gebilde beziehen". Friedrich Wilhelm Oscar August was born in 1840 in Berlin, and went to the university of this city where he followed lectures of Steiner, Ernst Eduard Kummer, and Karl Weierstrass, among others. After having completed his doctoral thesis in 1862 (on the use of imaginary objects in geometry, [August 1862]), he taught mathematics in several high-schools and in a school of artillery and engineering in Berlin: see the short autobiographical note inserted in his dissertation [August 1862, p. 40] and the necrology on pages $46-47$ of the 36th volume of Leopoldina (1900). The Jahrbuch über die Fortschritte der Mathematik counts 22 references having Friedrich August as their author, mostly published in Archiv der Mathematik und Physik and related to conics, cubics curves, and quadric surfaces; August also appears to have written quite a large number (774) of reviews for the Jahrbuch. Let us finally note that August seems now to be better-known in the field of cartography, notably for a particular conformal map that still bears his name [Snyder 1993, pp. 141-142].

81"[Die] Art von Sätzen, mit welchen die folgende Untersuchungen beschäftigt [...]" [August 1876b, p. 1].

82 “Ferner hat Steiner ähnliche Sätze angegeben über geschlossene Reihen von einander berührenden Kreisen und Kugeln [...]; endlich sind es die Steinerschen Sätze über Polygone bei Curven dritten Grades, die zu diesem Typus gehören.” [August 1876b, p. 2].

83"Die grosse Uebereinstimmung in diesen Sätzen lasst vermuten, dass sich dieselben von einem gemeinsamen Geschichtpunkte aus werden begründen lassen, und so zeigte sich denn auch in der analytischen Behandlungsweise, dass sowohl die Poncelet'schen Sätze, wie diejenigen über die Steiner'schen Polygone auf das Additionstheorem der elliptischen Integrale erster Gattung führten, wie dies Jacobi und Clebsch nachgewiesen haben. Obschon hierdurch der Zusammenhang jener Theoreme aufgedeckt ist, bleibt es doch wünschenswert, diesen Zusammenhang auch in geometrischer Weise klar zu legen, also einen Satz aufzufinden, aus welchem sich die genannten Theoreme durch möglichst einfache geometrische Betrachtungen ableiten lassen." 
character," ${ }^{4}$ to which his research could not be easily extended. Hence August explicitly included the previous theorems in the category of the theorems of closure, but he also admitted that his search for a common point of view would not encompass all the instances of this category. About these supplementary examples, he described the works of Darboux [1873] on generalizations of the theorem of Poncelet, added that "Herr Felix Klein had the kindness to attract [his] attention to a theorem of closure for geodesic polygons on surfaces of the second order," and mentioned another paper he himself published shortly before, in which he had proved a theorem "belonging to the domain of the theorems of closure." 85

As these formulations suggest, the label "theorems of closure" was used by August to designate a certain set, a "domain" of theorems which was not defined a priori as a determined agglomerate of fixed elements; rather, it seems that he perceived it as characterized by a certain property which allowed him in return to decide whether a theorem belongs to the domain or not - the use of an indefinite, singular article in the phrase "a theorem of closure," which was repeated by August several times, emphasizes this idea of a global category from which single entities could be inferred.

For his mathematical proofs, August started by considering what he called "generalized polygons of Steiner": he took a cubic curve with $2 n-1$ fixed points on it, and considered a variable inscribed $2 n$-gon whose $2 n-1$ first sides are supposed to pass through the fixed points. Then he proved that the last side of the polygon intersects the cubic curve in a fixed point (see figure 8 ). ${ }^{86}$

By an adequate use of projections, August deduced from this theorem a result about polygons inscribed in a spatial quartic curve of the first species, i.e. a curve arising as the intersection of two quadric surfaces. More precisely, August proved that if the $2 n-1$ first sides of a variable $2 n$-gon inscribed in such a curve all describe the generators of hyperboloids, then the last side also describes the generators of a hyperboloid. Afterwards he particularized this theorem to the case where all the hyperboloids coincide, and deduced that if it is possible to inscribe in a spatial quartic curve of the first species a $2 n$-gon of which the sides alternatively belong to the two families of generators of a hyperboloid containing the curve, then there exist infinitely many such $2 n$-gons. Again, adequate plane projections were then used to deduce the theorem of Poncelet, the theorem on Steiner's chains of circles, and generalizations of the latter (e.g. a version where circles are replaced by conics). ${ }^{87}$

The point of view developed by August, therefore, united the theorems on Poncelet's polygons, Steiner's polygons, and Steiner's chains of circles, yet in an asymmetric way. Indeed, its basis was the generalization of the Steiner's polygons which served to prove an analogous theorem on polygons inscribed in spatial quartic curves of the first species, which in turn could be projected to obtain the theorems on the interscribed polygons and the chains

\footnotetext{
84“"[D]iejenigen Schliessungstheoreme [...], die weniger einfachen Charakters sind.” [August 1876b, p. 2].

85"Herr Felix Klein in München hat die Güte gehabt, mich auf ein Schliessungssatz für geodätische Polygone auf Flächen zweiten Grades aufmerksam zu machen. Auch der im vorigen Teile (LVIII) p. 216 publicirte Lehrsatz, eine gewisse Raumcurve sechsten Grades betreffend, gehört dem Gebiet der Schliessungstheoreme an." The cited article is [August 1876a].

${ }^{86}$ August did not even indicate that the theorem of Steiner corresponds to the case where the fixed points alternatively coincide, yielding only two fixed points.

${ }^{87}$ For instance, August used the fact that it is possible to find a planar projection transforming the quartic curve into a conic, the spatial polygon being then projected on a plane polygon whose sides are tangent to the conic projection.
} 


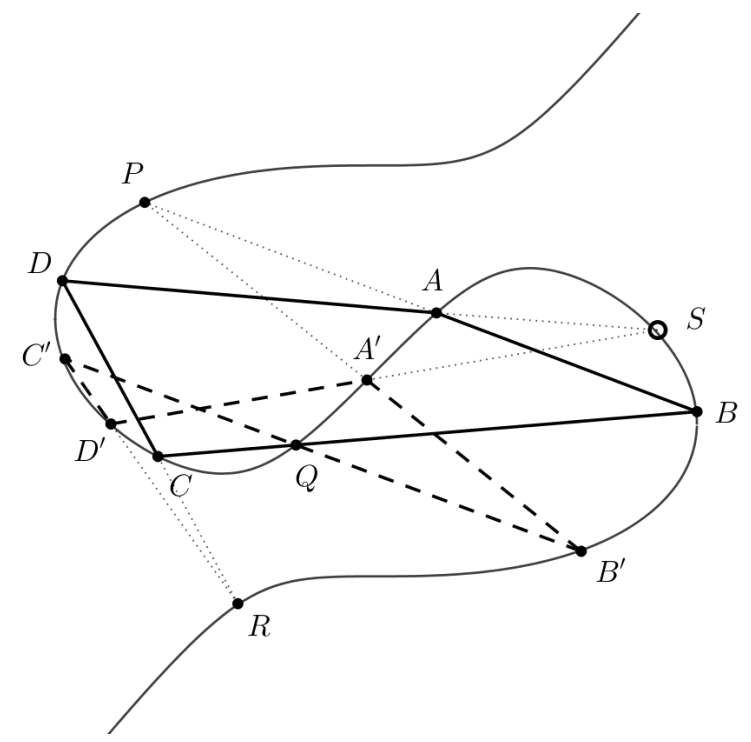

Figure 8 - Generalized Steiner polygons (with $n=2$ ). Three points $P, Q, R$ being supposed to be fixed on the curve, one considers polygons $A B C D$ and $A^{\prime} B^{\prime} C^{\prime} D^{\prime}$ inscribed in the curve, such that the sides $A B$ and $A^{\prime} B^{\prime}$ (resp. $B C$ and $B^{\prime} C^{\prime}$, resp. $C D$ and $C^{\prime} D^{\prime}$ ) pass through $P$ (resp. $Q$, resp. $R$ ). Then the sides $D A$ and $D^{\prime} A^{\prime}$ pass through the same point on the curve, here $S$.

of circles. August's desire to get rid of elliptic functions and to explain the unity of (some of) the theorems of closure with the "simplest possible geometric considerations" thus consisted in linking these theorems through projections from a spatial situation to several planar ones.

\subsection{Elliptic functions as the true source of the theorems of closure}

A completely different role was endorsed by elliptic functions in a 1876 paper of Simon called "Integral multiplication of elliptic functions in connection with the closure problem" [Simon 1876]. ${ }^{88}$ As Simon indicated in the introduction of the paper, he had already tackled the subject of the paper during the mathematical seminar in Berlin between 1864 and 1865, and this subject then led to his doctoral dissertation published shortly after, [Simon 1867]. ${ }^{89} \mathrm{He}$ started his paper by explaining that "just as the integral multiplication of cyclic functions is linked to the problem of the cyclotomy, that of elliptic functions is linked to that of the closure." 90

To explain this parallel, let us first recall that the problem of cyclotomy consists in dividing the circle into a number $n$ of equal parts; it is linked to the problem of determining

\footnotetext{
88"Ganzzahlige Mutliplication der elliptischen Functionen in Verbindung mit dem Schliessungsproblem."

${ }^{89}$ Simon studied at the University of Berlin between 1862 and 1866 . He taught mathematics in this city between 1868 and 1871, and was then appointed professor at the University of Strasbourg. One main difference between the disseration and the paper we discuss here is that the former only refers to the theorem of Poncelet and does not use any Schliessungs-word. About Simon's activities as an historian and didactician of mathematics, see [Volkert 1994].

90"Wie die ganzzahlige Multiplikation der cyklischen Functionen mit dem Problem der Kreistheilung zusammenhängt, so die der elliptischen mit dem der Schliessung.” [Simon 1876, p. 301].
} 
the complex numbers $\alpha$ such that $n \alpha$ is a period of the usual circular function $\exp (i \cdot)$. Another way to present it is to start from an initial argument $u$ and to search for the numbers $\alpha$ such that $\exp (i(u+n \alpha))=\exp (i u)$. Of course, the corresponding $\alpha$ are the same-they are such that $n \alpha$ is a period of the function $\exp (i \cdot)$-but what is important to note is that this condition is independent of $u .{ }^{91}$

As for the explanation of the link between the problem of closure and the multiplication of elliptic functions, it was presented by Simon in a (vague) paragraph contained in the introduction of the paper. Simon considered geometrical magnitudes of the form $(x, y, z \ldots)$, described by a parameter $t$, and took an interest in the sequences of such magnitudes corresponding to sequences $t_{1}, t_{2}, t_{3}, \ldots$ such that all the consecutive numbers $t_{k}$ and $t_{k+1}$ are linked by a relation $f\left(t_{k}, t_{k+1}\right)=0$ where $f(X, Y)$ is a symmetric polynomial which is of degree 2 both in $X$ and $Y .{ }^{92}$ Under these conditions, Simon asserted, an elliptic function $\chi$ exists, which can express the parameters $t_{k}$ in function of a new parameter $u$ (defined by $t_{1}$ ) and a constant $\alpha: t_{1}=\chi(u), t_{2}=\chi(u+\alpha), t_{3}=\chi(u+2 \alpha) \ldots$ With this, he stated that the sequence of the $t_{i}$ would be a "cycle" $t_{1}, \ldots, t_{n}$, i.e. one would have $t_{n+k}=t_{k}$ for all integer $k$, if $\chi(u+n \alpha)=\chi(u)$, that is, if $n \alpha$ be a period of the elliptic function $\chi$, a condition he noticed to be independent of $u$-whence the parallel with the cyclotomic case. ${ }^{93}$ Simon concluded:

Whenever a univocal progression is determined by fixation of $t$ and $\sqrt{R(t)}$ (where the degree of $R$ is no greater than 4), a theorem of closure is obtained. ${ }^{94}$ [Simon 1876, p. 301]

Simon thus presented a frame for the theorems of closure that was disconnected from any particular geometric incarnation, and in which these theorems were subsumed as mere instances of "the problem of closure," a problem whose generality is attested by the employed singular formulation. The theory of elliptic functions thus appeared as the root both explaining and producing these theorems.

Simon considered a first case, namely the Steiner polygons on cubic curves, and explained how the theory of elliptic functions could solve the corresponding problem. He considered a cubic curve given by an equation $y^{2}=4 x^{3}-g_{2} x-g_{3}$ and the associated parameterization $x=\wp(t), y=\wp^{\prime}(t)$ expressing the coordinates of the points of the curve thanks to the Weierstrass elliptic function $\wp$ and its derivative. ${ }^{95}$ Simon then proved that three points of

${ }^{91}$ The problem of cyclotomy, with its associated so-called cyclotomic equations, had been the subject (but not under this name) of the seventh chapter of Carl Friedrich Gauss's Disquisitiones Arithmeticae (1801), a chapter that assured the fame of the book and alimented the research on equation theory during the first decades of the nineteenth century. See [Goldstein and Schappacher 2007, pp. 18-24].

${ }^{92}$ This echoes the research of Rosanes and Pasch of 1869, which is cited at the end of Simon's introduction.

${ }^{93}$ Note that a parallel between circular functions and the cyclotomy on one hand, and the elliptic function associated to the lemniscate and its problem of division on the other hand, had already been emphasized by mathematicians like Gauss, Jacobi, and Abel at the beginning of the nineteenth century. See [Goldstein and Schappacher 2007, pp. 32-39].

94"Jedesmal also, wenn durch Fixirung von $t$ und $\sqrt{R(t)}$ (wo $R$ höchstens vom vierten Grade) ein eindeutiger Fortgang bestimmt wird, gilt ein Schliessugstheorem." The introduction of square root $\sqrt{R(t)}$ refers to the definition of an elliptic integral $\int \mathrm{d} t / \sqrt{R(t)}$, or to the definition of the inverse elliptic function.

${ }^{95}$ Simon neither commented the choice of the special equation $y^{2}=4 x^{3}-g_{2} x-g_{3}$ for a cubic curve, nor proved that every smooth cubic curve can be described by such an equation for an appropriate choice of coordinates. Let us note that Weierstrass had defined $\wp$ as a solution of the differential equation $s^{\prime 2}=4 s^{3}-g_{2} s-g_{3}$ in a lecture 
the curve defined by the parameters $t_{1}, t_{2}, t_{3}$ are aligned if and only if $t_{1}+t_{2}+t_{3} \equiv 0$ modulo the periods of $\wp$, and deduced from this characterization the theorem about the Steiner's polygons: he showed that if $\alpha, \beta$ are the parameters of the two fixed points in the construction of the polygons of Steiner, then the condition of closure is that $n(\alpha-\beta)$ is a (combination of the) period(s) of the Weierstrassian elliptic function. ${ }^{96}$

But Simon's main objective was to study the problem of the polygons of Poncelet or, as he wrote, "the most famous of the problems of closure." 97 Simon explained that there were three main questions to be solved: first, to prove the theorem of Poncelet itself; second, to express, in function of the invariants of the conics, the constants having the same role as that of the radii and the distance between the centers in the case of two circles; third, to find, in a simple way, the relations existing between these magnitudes and the number of sides of an interscribed polygon.

He also insisted on the fact that Jacobi was the very first to have tackled the problem of the polygons of Poncelet (in the case of two circles) by means of elliptic functions:

With the introduction of the addition theorem of elliptic functions, [Jacobi] discovered the true source of this theorem and of similar ones, and gave at the same time the general proof of the theorem and the relation between the constants of the problems, yet not in its simplest form. ${ }^{98}$ [Simon 1876, p. 303]

Then he acknowledged that these questions had already been treated by Cayley [1853a], Moutard [1862], and Rosanes and Pasch [1865], but explained that he allowed himself to return on the subject because of the simplicity of the formulas that he found [Simon 1876, p. 304]. ${ }^{99}$ We will not go into the technical details of Simon's research. Nevertheless, it is interesting to note that, in the previous quotation, Simon insisted again on the fact that elliptic functions, and especially the addition theorem, were the "true source" of the theorems of closure.

These theorems were thus united in Simon's work through a conception of them as arising from a common source, namely the elliptic functions. His general explanations, however, remained a bit unclear, and the theorems of Poncelet and of Steiner (about cubic curves) were the only ones that were mentioned and tackled by Simon-according to the titles and reviews of Simon's production listed in the Jahrbuch, it seems that he did not return to the subject of closure theorems later, and thus never gave other examples of theorems which would have their source in the theorem of addition of elliptic functions. ${ }^{100}$

given in 1863 [Bottazzini and Gray 2013, p. 428], which corresponds to the period of time when Simon was a student at the university of Berlin.

${ }^{96}$ Clebsch's 1864 solution of this problem was built on the elliptic functions of Jacobi, but relied on the same congruence (up to a constant) expressing the alignment of three points of the cubic, which led him to a similar condition on $n(\alpha-\beta)$, yet expressed in terms of the periods of the Jacobian functions. See [Lê 2018].

97"Ich wende mich nun zu dem bekanntesten unter den Schliessungsproblemen." [Simon 1876, p. 303].

98"Mit der Einführung des Additionstheorems der elliptischen Functionen deckt er selber die wahre Quelle dieser und aller ähnlichen Sätze auf und giebt zugleich den allgemeinen Beweis des Satzes und die Relation zwischen den Constanten des Problems, nur die letztere nicht in ihrer einfachsten Form."

${ }^{99}$ Let us remark that contrary to the works of Cayley, of Moutard, and of Rosanes and Pasch, Simon makes use of the Weierstrass elliptic function and the associated invariants, which seems to be connected to the issue of simplicity.

${ }^{100}$ This point of view is perhaps the one which is the closest to our current view on closure theorems, consisting in interpreting them as the search of points of finite order on some elliptic curves. For instance, [Griffith and Harris 1978] revisited the problem of Poncelet's polygon in this way. 


\subsection{A fundamental theorem of algebra}

Another kind of unification operated in the work of Adolf Hurwitz (1859-1919) entitled "On infinite-ambiguous geometric problems, particularly the problems of closure," one of his very first publications [Hurwitz 1879]. ${ }^{101}$ As the title indicates, Hurwitz aimed at investigating a certain set of problems containing the problems of closure, a set which he described as follows:

There are, in geometry, a large number of theorems stating that a certain event happens infinitely many times as soon as it happens once or a certain finite number of times. ${ }^{102}$ [Hurwitz 1879, p. 8]

Hurwitz did not specify the nature of the events in question, thus attributing some generality to the set of problems he was dealing with. The problems of closure, which were supposed to fit in this description, could correspond to the case where these events are the closure of sequences of geometrical objects like lines or circles satisfying additional conditions. ${ }^{103}$ But the nature of these events was no concern for Hurwitz's first reflections, focused on the general structure of the theorems described above:

The exterior form of these theorems already indicates the relation they have with the fundamental theorem of algebra according to which an equation with one unknown having a number of roots greater than its degree has infinitely many roots, being then satisfied by every value of the unknown. ${ }^{104}$ [Hurwitz 1879, p. 8]

This analogy between the geometric theorems and the fundamental theorem of algebra was then technically realized within the frame of $(m, n)$-correspondences. As Hurwitz explained, a $(m, n)$-correspondence is a way to associate two families of geometrical objects, both depending of one parameter, so that every object of the first family corresponds to $n$ objects of the second family, and reciprocally, that every object of the second family corresponds to $m$ objects of the first one. ${ }^{105}$ If the two families are made of objects of the same kind, a coincidence is an object which is associated to itself in the correspondence, and there exist in general $m+n$ coincidences in a $(m, n)$-correspondence. This notion of coincidence allowed Hurwitz to state a theorem according to which if a $(m, n)$-correspondence has more than $m+n$ coincidences, then every object is a coincidence. Hurwitz stressed that "[this] conclusion, according to which each element is a coincidence, comes from the fact that, under the

\footnotetext{
101"Ueber unendlich-vieldeutig geometrische Aufgaben, insbesondere über die Schliessungsprobleme." According to the Jahrbuch, the first publication of Hurwitz is an article of 1876 written together with Hermann Schubert, [Hurwitz and Schubert 1876]. The paper we examine here is his second one. Hurwitz attended lectures of Klein in Munich in 1877, and then spent the academic year 1877/1878 at the university of Berlin. For more biographical information about Adolf Hurwitz (and his brother Julius), and their works on continued complex fractions, see [Oswald and Steuding 2014].

102"Es giebt in der Geometrie eine grosse Anzahl von Sätzen, die aussagen, dass ein gewisses Ereignis unendlich oft Statt hat, sobald es nur ein Mal oder endlich oft eintritt."

${ }^{103}$ This distinction recalls our discussion about the inclusion of the theorems of closure within the porisms for the English mathematicians of the time.

104"Schon die äussere Form dieser Sätze weist auf den Zusammenhang hin, in welchen dieselben mit jenem Fundamentalsatze der Algebra stehen, dass eine Gleichung mit einer Unbekannten, die mehr Wurzeln hat als ihr Grad angiebt, unzählig viele Wurzeln besitzt, indem sie durch jede Werth der Unbekannten befriedigt wird." Thus the "fundamental theorem of algebra" mentioned by Hurwitz is not the one concerning the existence of roots of complex, non-constant polynomials. On this theorem and its different formulations, see [Gilain 1991].

${ }^{105}$ The particular case of $(2,2)$-correspondence is the same as the $(2,2)$-correlations used by Weyr.
} 
assumption that was made, the equation determining the coincidences of the correspondence is satisfied by every value of the unknown." 106

The idea behind this result is the following: a $(m, n)$-correspondence gives rise to an algebraic equation $f\left(\lambda_{1}, \lambda_{2}\right)=0$ between the parameters of the families in correspondence, an equation of degree $m$ in $\lambda_{1}$ and of degree $n$ in $\lambda_{2}$. The coincidences are parameterized by the solutions of the equation $f(\lambda, \lambda)=0$, which is of degree $m+n$. According to the algebraic theorem evoked by Hurwitz, if there exist more than $m+n$ coincidences, the equation has infinitely many solutions, and so every object is a coincidence. ${ }^{107}$

These general considerations were then applied to the particular case of the theorems of closure, and Hurwitz emphasized the simplicity allowed by the theorem on coincidences: "We now apply the previous theorem to the problems of closure, and we will see how easily the remarkable theorems to which they give rise follow." 108 Accordingly, the next four paragraphs of Hurwitz's paper were respectively devoted to Steiner's chains of circles, Poncelet's polygons, Steiner's polygons on cubic curves, and Weyr's polygons associated to spatial quartic curves of the first species. ${ }^{109}$ In each case, Hurwitz's method consisted in defining an adequate $(2,2)$-correspondence for which the coincidences are linked to closed polygons or chains of circles; the existence of one such closed sequence yielded a number of coincidence large enough to conclude that there are infinitely many coincidences and thus infinitely many closed polygons or chains or circles. ${ }^{110}$

Hence these four theorems of closure were presented as mere applications of one theorem on $(m, n)$-correspondences. This common root, and the exact same structure of their respective proofs, tended to reinforce their unity, a unity already seen through their "exterior form," as we saw above. The fundamental theorem of algebra thus appeared as a principle both explaining the resemblance of the formulations of the theorems of closure and underlying a common scheme of proof.

Let us finally remark that Hurwitz's intention of grounding the theorems of closure on a certain theorem of algebra differed from August's will to find a common geometric point of view on these problems, fuelled by the desire to exclude elliptic functions. In fact, Hurwitz published another paper shortly after, [Hurwitz 1882], in which he connected the approach of the (2,2)-correspondences with elliptic functions, and proved again the theorems about Steiner's polygons on cubics and chains of circles. If elliptic functions were thus used by Hurwitz to prove these theorems, he made no comment on a possible unifying role of these special functions for the category of the theorems of closure.

106“ $\mathrm{Zu}$ letzterem Schluss, dass jedes element Coincidenzelement ist, berechtigt uns der Umstand, dass die Gleichung, welche die Coincidenzen der betreffenden Correpsondenz bestimmt, unter der gemachten Voraussetzung, durch jeden Werth der Unbekannten befriedigt ist." [Hurwitz 1879, pp. 8-9].

${ }^{107}$ The existence of $m+n$ coincidences in general is called "correspondence principle" or "Chasles' correpsondence principle" in [Dieudonné 1974, p. 38] and [Del Centina 2016, p. 83]. The latter refers to the paper [Chasles 1864], where the result is stated on page 1175 .

108"Wir wenden nun den so oben aufgestellten Satz auf die Schliessungsprobleme an, und werden sehen, dass sich die bei letzteren auftretenden merkwürdigen Sätzen mit grosser Leichtigkeit dabei ergeben." [Hurwitz 1879, p. 9].

${ }^{109}$ In a last paragraph, Hurwitz also indicated, without giving any proof, that his method could also be applied to obtain some of the theorems that Darboux proved in [Darboux 1873].

${ }^{110}$ See [Del Centina 2016, pp. 88-89] for more details. 


\subsection{Three different partial unifications}

Each of the unifications that we have described in this section had its own operating mode. August first considered a geometric configuration which he depicted as a generalization of that of the polygons of Steiner associated to cubic curves; then he deduced some of the already-known theorems of closure with the help of different projections. His unifying approach thus consisted in deriving by means of geometric transformations the configurations linked to the closure theorems from an other configuration. On the other hand, Simon began by explaining how certain geometric problems could be expressed, one by one, with the theory of elliptic functions, and the core of the gathering of closure problems, then, was the problem of the division of the periods of these functions: the unification came from the possibility of reducing each closure problem to the problem of the division. Hurwitz, for his part, started by emphasizing the particular formulation of some geometric theorems, a formulation that he immediately linked with the fundamental theorem of algebra. Each of the usual closure theorems then appeared as examples of application of this theorem, or rather, of its version expressed with the theory of correspondences.

Hence these unifications were technically organized in different manners, and their authors situated them in specific, distinct domains of mathematics, namely geometry, the theory of elliptic functions, and algebra. Yet they shared the feature that, from an effective point of view, they were only partial unifications. Indeed, August emphasized this point himself when he explained that his approach could only reach a restricted part of the theorems of closure, and we saw that both Simon and Hurwitz applied their general principles to a small number of these theorems. This observation thus displays an interesting phenomenon, viz. a tension between statements announcing unifications in a general and somewhat vague way on one hand, and effective, technical, but incomplete realizations of them on the other hand.

Whatever their claimed disciplinary membership, the completion of their unifying role, or their actual ability to encompass all the problems of closure, the approaches of August, Simon, and Hurwitz tended to strengthen the category as they explicitly sought for reasons concealed behind the wordings of these problems. Therefore their respective papers represent a decisive step in the process of constituting of the category of the problems of closure, as they deliberately designated them with the label Schliessungsprobleme and presented unifying viewpoints explaining them as a whole.

\section{Between novelty and old issues, 1880-1907}

Before turning to our general conclusions, let us describe in this section the content of the publications of the corpus published from the beginning of the 1880s. We will be briefer here, trying to delineate the general themes which can be observed in this part of the corpus and which are relevant for our purpose. These themes are for the most part reminiscent of what we already described earlier about extensions, analogies, mathematical links, and alternative methods; but in this part of the corpus, they are explicitly linked to the labels like Schliessungssätze.

A number of publications in the period 1880-1907 aimed at tackling some already-known geometric situations with other methods than those used before. Let us take a look at the 
case of the theorem of the polygons of Steiner on cubics. Like the works of Weyr [1870, 1871] and, in a way, of August [1876b] which we depicted before, several texts had the objective to come back to the proof of this theorem and of diverse subsequent properties of the polygons of Steiner, especially with the intention to avoid the theory of elliptic functions and to suggest alternative "geometric" methods. For instance, in 1883, Pieter Hendrik Schoute (1846-1913), professor of mathematics at the university of Groningen, wrote that "the problems of closure that Steiner proposed almost 40 years ago in the 32nd volume of [Crelle's] journal are still waiting for a geometrical solution" 111 [Schoute 1883, p. 105]. He acknowledged that Clebsch [1864] had solved the problem for smooth cubic curves with elliptic functions and remarked that Weyr had to use differential calculus to complete his approach, so that a "geometric" proof, covering both the cases of smooth and of singular cubics, was still needed-apparently, Schoute did not know of the research of August. After this work of Schoute, other publications tackled the same questions, each presenting their own priorities. To take but one example, in 1888, Martin Disteli (1862-1923) published a monograph in which, as its title indicates, he wanted to tackle the theorem of Steiner with methods of descriptive geometry [Disteli 1888]. ${ }^{112}$ For him, these methods had the advantage of encompassing both the smooth and the singular cases of cubic curves, contrary to those based on elliptic functions. But Disteli also stressed that descriptive geometry addressed the issue of the graphical representation of the obtained results, for it yielded "the simplest constructive means to actually represent" them [Disteli 1888, pp. IV-v] (see figure 9).

Other publications were devoted to new geometric situations, frequently presented as extensions of the problems of Poncelet's polygons, of Steiner's polygons, or (to a lesser extent) of Steiner's chains of circles. This is the case of Henry Picquet, a French répétiteur at the École polytechnique, who proposed a memoir aiming at studying polygons that are both inscribed in, and circumscribed to a single cubic curve-in other words, these polygons have their vertices on the curve, and their sides are tangent to it [Picquet 1884]. If Picquet made an extensive use of elliptic functions in this research, works of other mathematicians were later developed to bypass these functions, just like in the previously noted situations. ${ }^{113}$ Other typical examples of successive extensions of aldready-known problems are that of Frank Morley, who made investigations on polygons interscribed between two cubic curves [Morley 1907], and of Henry White, whose research about polygons interscribed between a conic and a cubic was explicitly presented in a frame implying the original situation as well as the more recent related works: "Poncelet's porism of the inscribed and circumscribed polygons has a certain extension to the system of a non-singular plane cubic and a curve of the second class, resembling that recently given by Morley to point cubic and line cubic" [White 1906]. ${ }^{114}$ Such extensions hence recall the situation of the first decades of the nineteenth century, and

111"Die Schliessungsprobleme, welche Steiner vor fast vierzig Jahren im 32. Bande dieses Journals (Seite 182-184) aufgestellt hat, warten noch immer einer geometrischen Lösung." Here, the plural form of Schliessungsprobleme refers to the cases of cubics and of binodal quartics.

${ }^{112}$ The monograph is entitled "Die Steiner'schen Schliessungsprobleme nach darstellend geometrischer Methode," which can be translated as "The problems of closure of Steiner with methods of descriptive geometry." Disteli had been the student of Wilhelm Fiedler, the famous translator of George Salmon's books on geometry and invariant theory. In 1888, Disteli was assistant professor at the Eidgenössische Polytechnikum in Zürich. For biographical information about him, see [Frei and Stammbach 1994, p. 23].

${ }^{113}$ See for instance a paper of Eduard Weyr's brother Emil, [Emil Weyr 1893].

${ }^{114}$ The paper of Morley which we just mentioned and which is alluded to by White is dated 1905, which explains the apparent chronological inversion in this quotation. 

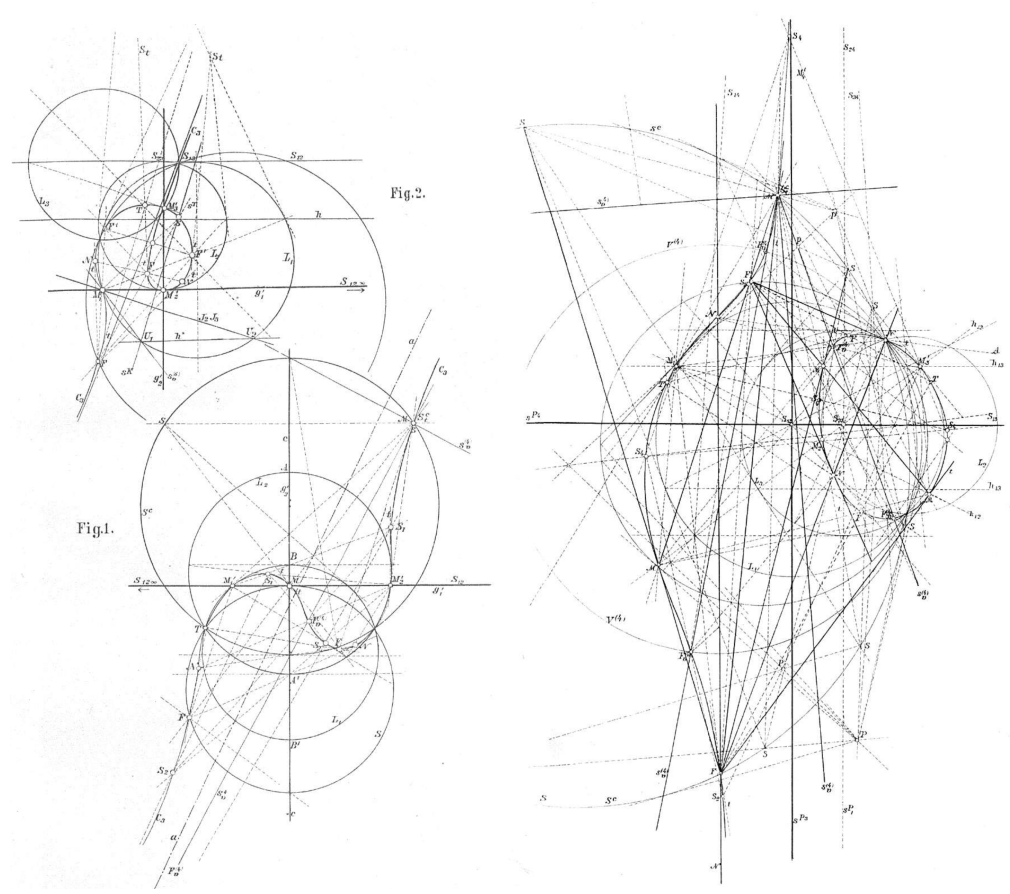

Figure 9 - Examples of Disteli's simple means of representation of the results on cubic curves, [Disteli 1888, tables III and VI].

they surely contributed to gather all the corresponding problems and theorems as a coherent whole.

Two other factors, similar to the ones that have been already noted in the previous sections, also tended to aggregate them: on the one hand, the demonstrations of technical links connecting together two situations that were a priori perceived as different, and, on the other hand, the emphasis put on the analogies existing between different problems. To illustrate the first of these factors, let us only, and very briefly, mention the polygons of Steiner inscribed in a cubic and the polygons inscribed in a spatial quartic of the first species whose sides alternatively belong to the two families of generators of a quadric surface. In a paper devoted to particular quartic surfaces, Friedrich Schur proved that these two sorts of polygons are linked by various geometric transformations (like projections), [Schur 1882]. ${ }^{115}$ As for the analogies, we refer to a paper of Otto Staude devoted to geodesic polygons drawn on a quadric surface [Staude 1883]. In this paper, Staude explained that two ways of constructing ellipses could be extended to space in order to construct quadric surfaces, and he added:

Accordingly, Poncelet's theorems of closure display a double analogy within the geometry of quadric surfaces: on the one hand, with the theory of the geodesic polygons on quadric surfaces, and on the other hand, with the theory of the rectilinear polygons that are circumscribed about two quadrics and inscribed in a third one. In both of these theories, one can search for an application of hyperelliptic integrals which is analogous to the application that elliptic integrals have found in [Jacobi 1828] for the first time. ${ }^{116}$

\footnotetext{
${ }^{115}$ The surfaces tackled by Schur in this paper have the particularity to contain exactly 64 straight lines, a number which is now known to be the maximal number of lines in a (complex) non-singular quartic surface.

116"Entsprechend finden die Poncelet'schen Schliessungssätze innerhalb der Geometrie der Flächen 2. Grades
} 
[Staude 1883, pp. 219-220]

Thus the analogy operated on different levels: to introduce the subject of the paper (here, the geodesic polygons on quadric surfaces), and to explain the transfer of method that was about to be made in the technical details, with the use of hyperelliptic integrals. Here again, this kind of remarks brings to mind what we described above: for instance, the transfer of method of Staude recalls Clebsch's comments in the introduction of his 1864 paper on the polygons of Steiner.

As some of the descriptions we just made indicate, the Schliessungs-labels were employed quite frequently in this last part of the corpus. To be more specific, three different kinds of uses can be distinguished. We find again the plural forms "closure theorems" and "closure problems" to designate a set of theorems or problems associated to different geometric situations: this is exemplified by Viktor Eberhard, who talked about "the theory of the problems of closure," in a work where he endeavored to link the polygons inscribed in a cubic with those inscribed in a spatial quartic curve [Eberhard 1887, p. 68]. ${ }^{117}$ But the labels in question also appeared in the context of a single geometric situation, sometimes in a singular form — as in "the theorem of closure of Steiner" [Schröter 1888, p. 256] -and sometimes in a plural form - as in "the theorems of closure of Poncelet" [Thomae 1895, p. 352]. The difference between these two sorts of occurrences is that the former bore upon the main theorem stating the alternative about the existence of closed polygons, whereas the latter alluded to the main theorem as well as the supplementary properties that Poncelet had proved alongside, like the concurrency of the diagonals of all the closed quadrilaterals. Finally, echoes of these labels also appeared in disguised forms, through phrases like "closure conditions," "closure ratios," or "closure numbers" that can be find, for instance, in [Vahlen 1896, pp. 154, 160]. ${ }^{118}$

These numerous and varied uses of the Schliessungs-labels show their diffusion, adoption, and establishment during the two last decades of the nineteenth century. Alongside the other features we described, this suggests that at this time, the problems of closure were indeed recognized as a proper category, with its typical issues and concerns. But it also had its own history, a history that often appeared through names and references associated to specific objects and approaches, and linked to mathematicians who belonged to previous generations, like Poncelet, Steiner, or Jacobi.

\section{Categorization, classification, and family resemblance}

The descriptions that have been made in this paper show that the category of the theorems of closure has been built gradually and collectively during the nineteenth century. In the

eine doppelte Analogie; es stellt sich nämlich über dieselben einerseits die Theorie der geodätische Polygone auf den Flächen 2. Grades, welche einer Krümmungscurve umbeschrieben und einer andern einbeschrieben sind, anderseits die Theorie der geradlinigen Polygone, welche zweien Flächen 2. Grades umbeschrieben und einer dritten einbeschrieben sind. In beiden Theorien kann man eine Anwendung der hyperelliptische Integrale suchen analog derjenigen, welche die elliptische Integrale zuerst in der Arbeit von Jacobi [...] gefunden haben."

${ }^{117}$ Let us remark that the evocation of a "theory" of closure theorems brings out the idea of a proper set of propositions and questions associated to these theorems.

${ }^{118}$ Theodor Vahlen talked about "Schliessungsbedingungen," "Schliessungsverhältnisse," but also "Schliessungszahl," to designate the conditions, the metric relations, and some of the numbers implied in these relations linked to the closing chains of circles of Steiner. 
first decades of the century, the theorems on the polygons of Poncelet and on the chains of circles of Steiner were still separate theorems, even though they generated similar issues (e.g. their analogical extensions to spatial or spherical objects, or the search for metrical relations expressing the existence of closed series of geometrical objects) that were tackled by different mathematicians. Quite similarly, in the middle of the century, the two theorems of Steiner about the polygons inscribed in cubic curves and in binodal quartic curves were not explicitly connected to with one another, but their wordings, their close textual position within the same paper, and the uses of the semantic field of analogy contributed to display them as siblings. After a few works of the 1860s which evoked the existence of a certain class of problems, the label Schliessungsprobleme appeared in the 1870 paper of Eduard Weyr to encompass the two latter theorems of Steiner. The label and its variants subsequently disseminated, as their appearances in the writings of numerous mathematicians attest: the papers of August, Simon, and Hurwitz who evidenced the unity of the category with technical reasons, and the many later articles of others who extended, transposed, or found new proofs of already-known theorems of closure.

These elements are traces of the actions which, taken as a whole, manifest the historical process of the emergence of the category of closure theorems. But now that we have arrived at the end of our study, one question, which tacitly came up in several places above, remains unsolved: on what basis did the mathematicians of the last third of the nineteenth century recognize a given theorem to be a theorem of closure? In other words, what was the process of categorization that operated in their mind in order to decide whether a theorem should be grouped among the theorems of closure or not? This question bears upon the cognitive mechanisms which grounded the mental recognition of closure theorems by mathematicians of the past, and, especially because of the lack of historical material, I do not claim to be in position to give a definitive answer to it. Nevertheless, I would like to propose some related reflections in light of what has been done in the present paper.

There exist many variations of the notion of categorization in cognitive science, each of them having peculiarities which reflect the priorities of their authors or of the sub-discipline in which they have been developed. ${ }^{119}$ Here I choose to confront the case of the theorems of closure with two usual acceptations of the notion: the so-called "classical" one, inherited from Aristotle, and the one based on Ludwig Wittgenstein's concept of "family resemblance." 120

On the one hand, the classical view conceives categories as "predetermined categories, each defined by a set of essential features represented by the category label; and all members of a given category [are] assumed to share a set of essential features that [is] identified by the category label and [is] apprehended by all members of the linguistic community." [Jacob 2004, p. 520]. Therefore, from this viewpoint, people categorize on the basis of lists of necessary and sufficient conditions defining each category and allowing to check the membership of a given object to a given category. Let us note that within the framework of mathematics, this view may be connected with the notion of classification, in the sense of a systematic

\footnotetext{
${ }^{119}$ For an overview on the subject, see the extensive [Cohen and Lefebvre 2017].

${ }^{120}$ The following explanations come in part from [Jacob 2004], in which the differences between these two viewpoints are synthetically and clearly presented. As Ivahn Smadja rightly pointed out to me, other tracks than that of Wittgenstein could have been followed here. My choice to confront the case of the theorems of closure to this well-known distinction between the classical acceptation of categorization and Wittgenstein's family resemblance is meant to bring to light a number of observations and questions through one particular prism, and is not intended to provide a definitive answer to the discussion.
} 
distribution of objects into classes according to chosen principles: classifying integers according to their parity, classifying algebraic curves according to their genus, etc. ${ }^{121}$

On the other hand, the acceptation of categorization coming from Wittgenstein's works is rooted in his notion of "family resemblance," a notion he proposed in his Philosophical Investigations as he was attempting to account for what constitutes the category of games [Wittgenstein 1953]. "While traditional classification is rigorous in that it mandates an entity either is or is not a member of a particular class, the process of categorization [based on family resemblance] is flexible and creative and draws nonbinding associations between entities - associations that are based not on a set of predetermined principles but on the simple recognition of similarities that exist across a set of entities." [Jacob 2004, p. 527]. According to this description, categorization is made by subjects through a perception of resemblance (the family resemblance) among certain given objects, which are then gathered as a proper category. Using a mathematical example, Wittgenstein himself insisted on the fact that the actual delimitation of categories is not an issue from this point of view:

\begin{abstract}
"All right: the concept of number is defined for you as the logical sum of these individual interrelated concepts: cardinal numbers, rational numbers, real numbers, etc.; and in the same way the concept of a game as the logical sum of a corresponding set of sub-concepts."- It need not be so. For I can give the concept "number" rigid limits in this way, that is, use the word "number" for a rigidly limited concept, but I can also use it so that the extension of the concept is not closed by a frontier. And this is how we do use the word "games." [...]

How should we explain to someone what a game is? I imagine that we should describe games to him, and we might add: "This and similar things are called 'games." [Wittgenstein 1953, §§ 68-69]
\end{abstract}

In what way do these considerations illuminate the case of the category of closure theorems? First, as the present study showed, no mathematician of the nineteenth century proposed a definition of what these theorems, seen as a whole, would be; none of them evoked a list of criteria that should be checked to evaluate the membership of a given theorem to the category. Furthermore, the creation of the label Schliessungssätze and its variants did not appear in a general context of classification of every geometric problems and theorems, but rather served to gather a number of disparate propositions into one identified category. Besides, even the three approaches of August, Simon, and Hurwitz, which could be interpreted as means to make explicit the delimitation of the category of closure theorems, were not presented in this way: each of these works was intended to explain the unity of (some of) the theorems of closure, and have been developed by their authors while placing boundaries around the category was not an issue. ${ }^{122}$ These observations thus indicate that the classical view is not relevant to account for the categorization process of the theorems of closure.

On the contrary, the previous quotation of Wittgenstein could well be used when replacing "games" by "closure theorems": in light of our reading of the texts of the nineteenth century, one could be tempted to define the theorems of closure by describing some of them (like

\footnotetext{
${ }^{121}$ The word "classification" is also used in [Jacob 2004] in this sense. Practices of classifications in the history of science (especially in the nineteenth century) are the topic of a special volume of Cahiers François Viète, [Lê and Paumier 2016b].

${ }^{122}$ Moreover, les us recall that these approaches were only partial, from an effective viewpoint.
} 
the theorem of Poncelet, or those of Steiner) and then by adding: "This and similar things are called "closure theorems." "Moreover, the particular wordings of the theorems, which appeared frequently without being explicitly commented, as well as the vague hints to the "exterior form" of the theorems, and the numerous extensions and analogies that tended to implicitly aggregate them as a whole, also plead in favor of a categorization process grounded on family-resemblance-like mechanisms. Borrowing Wittgenstein's well-known metaphor may eventually help sum up and illuminate the situation: the thread of the theorems of closure had no fiber going through its entire length-excepting, perhaps, the theorem of Poncelet - but its strength came from the way all its fibers were connected to one another by mathematicians creating and using specific labels, building analogical bridges, transposing particular wordings, or searching for unity among some of these fibers. ${ }^{123}$

In different ages and places, practitioners of mathematics have distinguished and forged many categories such as disciplinary rubrics, families of objects, and classes of problems. But what can be told about the diverse processes, both historical and cognitive, which have grounded the creation of these categories? For a trained mathematician, recognizing an even integer is certainly different from assigning a given paper into a rubric like "geometry." Likewise, there is no doubt that identifying kinds of cubic surfaces on the basis of their visible shape and classifying them according to their "topological type" (a notion defined in order to make rigorous the idea of similarity of shape) ${ }^{124}$ are two actions grounded by different cognitive processes, even if the latter has been inspired by the former.

The case study that I analyzed here sheds some light on a particular kind of categorization that has been progressively conducted by mathematicians throughout the nineteenth century, each of them having proceeded by family resemblance rather than by strict classification. Yet the previous example of cubic surfaces and the constant evolution of mathematics raise the question of the possible shifts between these two notions of categorization: are objects or theorems that have been once categorized by similarity meant to become later the elements of a definite class in an exhaustive, systematic, and formalized classification?

\section{Acknowledgments}

I would like to warmly thank Jemma Lorenat for her pertinent suggestions, especially about Steiner, and for her linguistic corrections. My acknowledgments also go to Ivahn Smadja, Catherine Goldstein, and to the two anonymous reviewers, who helped improve the paper.

\section{References}

Abel, Niels Henrik, Clausen, Thomas, and Steiner, Jacob (1827), “Aufgabe und Lehrsätze, erstere aufzulösen, letztere zu beweisen", Journal für die reine und angewandte Mathematik 2, pp. 286-292.

August, Friedrich (1862), "Disquisitiones de superficiebus tertii ordinis", $\mathrm{PhD}$ thesis, Berlin: Universitate Friderica Guilelma Berolinensi.

\footnotetext{
${ }^{123}$ The metaphor of the thread has also been used in [Goldstein 1989] to account for a non-linear, collective process of constitution of a mathematical notion, the circle.

${ }^{124}$ Different shapes of cubic surfaces have been described by Klein in 1873, while the notion of topological type has been developed at the end of the 1980s. See [Lê and Paumier 2016a, p. 25] and the references given therein.
} 
August, Friedrich (1876a), "Lehrsatz, eine gewisse Raumcurve sechsten Grades betreffend", Archiv der Mathematik und Physik 58, pp. 216-218.

— (1876b), "Ueber die Zusammenhang gewisser Sätze, welche sich auf geschlossene Reihen geometrischer Gebilde beziehen", Archiv der Mathematik und Physik 59, pp. 1-17.

Barbin, Évelyne and Guitart, René (2001), "Algèbre des fonctions elliptiques et géométrie des ovales cartésiennes", Revue d'histoire des mathématiques 7 (2), pp. 161-205.

Bečváŕ, Jindřich (ed.) (1995), Eduard Weyr, Prague: Prometheus.

Bernard, Alain (ed.) (2015), "Les Séries de problèmes, un genre au carrefour des cultures", SHS Web of Conferences 22.

Bos, Henk J. M., Kers, Cees, Oort, Frans, and Diederick, Raven (1987), "Poncelet's Closure Theorem", Expositiones Mathematicae 5, pp. 289-364.

Bottazzini, Umberto and Gray, Jeremy (2013), Hidden Harmony-Geometric Fantasies: The Rise of Complex Functions, New York: Springer.

Brechenmacher, Frédéric (2010), "Une histoire de l'universalité des matrices mathématiques", Revue de synthèse 131 (4), pp. 569-603.

Brill, Alexander, Gordan, Paul, Klein, Felix, Lüroth, Jacob, Mayer, Adolph, Noether, Max, and Mühll, Karl von der (1873), "Rudolf Friedrich Alfred Clebsch - Versuch einer Darlegung und Würdigung seiner wissenschaftlichen Leistungen", Mathematische Annalen 7, pp. 155.

Cantor, Moritz (1857), "Ueber die Porismen des Euclid und deren Divinatoren", Zeitschrift für Mathematik und Physik 2, pp. 17-57.

Cayley, Arthur (1853a), "Correction of Two Theorems Relating to the Porism of the In-andcircumscribed Polygon", Philosophical Magazine 6, pp. 376-377.

- (1853b), "Note on the Porism of the In-and-circumscribed Polygon", Philosophical Magazine 6, pp. 99-102.

- (1853c), "On the Geometrical Interpretation of the Integral $\int \mathrm{d} x \div \sqrt{(x+a)(x+b)(x+c)}$ ", Philosophical Magazine 5, pp. 281-284.

- (1857), "Supplementary Remarks on the Porism of the In-and-circumscribed Triangle", Philosophical Magazine 13, pp. 19-30.

- (1861), "On the Porism of the In-and-circumscribed Polygon", Philosophical Transactions of the Royal Society of London 151, pp. 225-239.

— (1871a), "A 'Smith's Prize' Paper; Solutions", The Oxford, Cambridge and Dublin Messenger of Mathematics 5, pp. 182-203.

- (1871b), "On the Porism of the In-and-circumscribed Polygon, and the $(2,2)$ Correspondence of Points on a Conic", The Quarterly Journal of Pure and Applied Mathematics 11, pp. 83-91.

- (1895), The Collected Mathematical Papers of Arthur Cayley, vol. 8, Cambridge: Cambridge University Press.

Chapple, William (1749), "An Essay of the Properties of Triangles Inscribed in, and Circumscribed about Two given Circles”, Miscellanea curiosa mathematica 1, pp. 117124.

Chasles, Michel (1860), Les Trois livres de Porismes d'Euclide, Paris: Mallet-Bachelier.

- (1864), "Considérations sur la méthode générale exposée dans la séance du 15 février", Comptes rendus des séances de l'Académie des sciences 58, pp. 1167-1175. 
Chemla, Karine (1998), "Lazare Carnot et la généralité en géométrie. Variations sur le théorème dit de Menelaus", Revue d'histoire des mathématiques 4, pp. 163-190.

- (2009), "On Mathematical Problems as Historically Determined Artifacts: Reflections Inspired by Sources from Ancient China”, Historia Mathematica 36, pp. 213-246.

Chorlay, Renaud (2010), "From Problems to Structures: The Cousin Problems and the Emergence of the Sheaf Concept", Archive for History of Exact Sciences 64 (1), pp. 1-73.

Clebsch, Alfred (1864), "Ueber einen Satz von Steiner und einige Punkte der Theorie der Curven dritter Ordnung", Journal für die reine und angewandte Mathematik 63, pp. 94-121.

Cohen, Henri and Lefebvre, Claire (eds.) (2017), Handbook of Categorization in Cognitive Science, 2nd ed., Amsterdam, Oxford, Cambridge: Elsevier.

Croizat, Barnabé (2016), "Gaston Darboux : naissance d'un mathématicien, genèse d'un professeur, chronique d'un rédacteur", $\mathrm{PhD}$ thesis, Université Lille 1.

Darboux, Gaston (1873), Sur une classe remarquable de courbes et de surfaces algébriques et sur la théorie des imaginaires, Paris: Gauthier-Villars.

Del Centina, Andrea (2016), "Poncelet's Porism: A Long Story of Renewed Discoveries", Archive for History of Exact Sciences 70, pp. 1-122, 123-176.

Dieudonné, Jean (1974), Cours de géométrie algébrique, vol. 1. Aperçu historique sur le développement de la géométrie algébrique, Vendôme: Presses Universitaires de France.

Dingeldey, Friedrich (1903), "Kegelschnitte und Kegelschnittsysteme”, in, Encyklopädie der mathematischen Wissenschaften mit Einschluss ihrer Anwendungen, vol. III. C. 1. Leipzig: Teubner, pp. 1-160.

Disteli, Martin (1888), Die Steiner'schen Schliessungsprobleme nach darstellend geometrischer Methode, Leipzig: Teubner.

Durand-Richard, Marie-José (ed.) (2008), L'Analogie dans la démarche historique : Perspective historique, Paris: L'Harmattan.

Durrande, J. B. (1823/1824), "Démonstration élémentaire des principales propriétés des hexagones inscrits et circonscrits au cercle, suivie de la solution de divers problèmes de géométrie”, Annales de Mathématiques pures et appliquées 14, pp. 29-62.

Eberhard, Viktor (1887), "Die Raumcurven vierter Ordnung erster und zweiter Species in ihrem Zusammenhang mit den Steiner'schen Schliessungsproblemen bei den ebenen Curven dritter Ordnung", Zeitschrift für Mathematik und Physik 32, pp. 65-82, 129-144.

Frei, Günther and Stammbach, Urs (1994), Die Mathematiker an den Zürcher Hochschulen, Basel: Springer.

Friedelmeyer, Jean-Pierre (2007), "Le Théorème de clôture de Poncelet, une démonstration 'imparfaite', qui fait toute une histoire. ..”, in Évelyne Barbin and Dominique Bénard (eds.), Histoire et enseignement des mathématiques - Rigueurs, erreurs, raisonnements, Institut National de Recherche Pédagogique - Université Blaise-Pascal de ClermontFerrand (IREM), pp. 229-261.

- (2011), "L'Impulsion originelle de Poncelet dans l'invention de la géométrie projective", in, Éléments d'une biographie de l'Espace projectif, Nancy: Presses Universitaires de Nancy, pp. 55-158.

Fuss, Nicolas (1798), "De quadrilateris quibus circulum tam inscribere quam circumscribere licet", Nova Acta Academiae Scientiarum imperialis Petropolitanae 10 (année 1792), pp. 103-125. 
Fuss, Nicolas (1802), "De polygonis symmetrice irregularibus circulo simul inscriptis et circumscriptis", Nova Acta Academiae Scientiarum imperialis Petropolitanae 13 (années 1795-1796), pp. 166-189.

Gandon, Sébastien (2005), "Pasch entre Klein et Peano : empirisme et idéalité en géométrie", Dialogue 14, pp. 653-692.

Gilain, Christian (1991), "Sur l'histoire du théorème fondamental de l'algèbre : théorie des équations et calcul intégral", Archive for History of Exact Sciences 42, pp. 91-136.

- (2010), "La Place de l' analyse dans la classification des mathématiques : de l'Encyclopédie à la Méthodique", Recherches sur Diderot et sur l'Encyclopédie 45, pp. 109-128.

Gispert, Hélène (1999), "Les Débuts de l'histoire des mathématiques sur les scènes internationales et le cas de l'entreprise encyclopédique de Felix Klein et Jules Molk", Historia Mathematica 26, pp. 344-360.

Goldstein, Catherine (1989), "L'un est l'autre : pour une histoire du cercle", in Michel Serres (ed.), Éléments d'histoire des sciences, Paris: Bordas, pp. 129-149.

- (2013), "Routine Controversies: Mathematical Challenges in Mersenne's Correspondence", Revue d'histoire des sciences 66 (2), pp. 249-273.

Goldstein, Catherine and Schappacher, Norbert (2007), "A Book in Search of a Discipline”, in Catherine Goldstein, Norbert Schappacher, and Joachim Schwermer (eds.), The Shaping of Arithmetic after C. F. Gauss's Disquisitiones Arithmeticae, Berlin: Springer, pp. 3-65.

Griffith, Phillip A. and Harris, Joseph (1978), “On Cayley's Explicit Solution to Poncelet's Porism”, L'Enseignement mathématique, 2nd ser. 24, pp. 31-40.

Halphen, Georges-Henri (1886), Traité des fonctions elliptiques et de leurs applications, vol. 1, Paris: Gauthier-Villars.

Hart, Andrew (1858), "On the Porism of the In-and-circumscribed Triangle", The Quarterly Journal of Pure and Applied Mathematics 2, p. 143.

Heath, Thomas (1911), "Porism”, in Hugh Chisholm (ed.), Encyclopcedia Britannica, 11th ed., vol. 22, Cambridge University Press, pp. 102-103.

- (1921), A History of Greek Mathematics, 2 vols., Oxford: Clarendon Press.

Hurwitz, Adolf (1879), "Ueber unendlich-vieldeutige geometrische Aufgaben, insbesondere über die Schliessungsprobleme", Mathematische Annalen 15, pp. 8-15.

- (1882), "Ueber die Anwendung der elliptischen Functionen auf Probleme der Geometrie", Mathematische Annalen 19, pp. 56-66.

Hurwitz, Adolf and Schubert, Hermann (1876), "Ueber den Chasles'schen Satz $\alpha \mu+\beta v$ ", Nachrichten von der Königlichen Gesellschaft der Wissenschaften und der Georg-AugustsUniversität, pp. 503-517.

Jacob, Elin K. (2004), "Classification and Categorization: A Difference that Makes a Difference", Library Trends 52 (3), pp. 515-540.

Jacobi, Carl Gustav Jacob (1828), "Ueber die Anwendung der elliptischen Transcendenten auf ein bekanntes Problem der Elementargeometrie: 'Die Relation zwischen der Distanz der Mittelpuncte und der Radien zweier Kreise zu finden, von denen der eine einem unregelmässigen Polygon eingeschrieben, der andere demselben umgeschrieben ist'", Journal für die reine und angewandte Mathematik 3, pp. 376-389.

- (1829), Fundamenta nova theoriae functionum ellipticarum, Berlin: Bornträger.

- (1845), "Sur l'application des transcendantes elliptiques à ce problème connu de géométrie : Trouver la relation entre la distance des centres et les rayons de deux cercles 
dont l'un est circonscrit à un polygone irrégulier et dont l'autre est inscrit à ce même polygone", Journal de Mathématiques pures et appliquées 10, pp. 435-444. trad. Olry Terquem.

Knobloch, Eberhard (1991), "L'Analogie et la pensée mathématique", in Roshdi Rashed (ed.), Mathématiques et Philosophie de l'Antiquité à l'Âge classique, Paris: Éditions du CNRS, pp. 217-237.

Kohn, Gustav (1908), "Ebene Kurven dritter und vierter Ordnung", in, Encyklopädie der mathematischen Wissenschaften mit Einschluss ihrer Anwendungen, vol. III. 2. 1. Leipzig: Teubner, pp. 457-570.

Lê, François (2016), "Reflections on the Notion of Culture in the History of Mathematics: The Example of 'Geometrical Equations'", Science in Context 29 (3), pp. 273-304.

- (2018), "Le Paramétrage elliptique des courbes cubiques par Alfred Clebsch", Revue d'histoire des mathématiques 24, pp. 1-39.

Lê, François and Paumier, Anne-Sandrine (2016a), "De la science comme classification à la classification comme pratique scientifique : quelques réflexions à partir de deux cas mathématiques", Cahiers François Viète, 3rd ser. 1, pp. 9-33.

- (eds.) (2016), "La Classification comme pratique scientifique", Cahiers François Viète, 3rd ser. 1.

Lorenat, Jemma (2012), "Not Set in Stone: Nineteenth-century Geometrical Constructions and the Malfatti Problem", BSHM Bulletin: Journal of the British Society for the History of Mathematics 27, pp. 169-180.

- (2016), "Synthetic and Analytic Geometries in the Publications of Jakob Steiner and Julius Plücker (1827-1829)", Archive for History of Exact Sciences 70 (4), pp. 413-462.

- (2017), "Radical, Ideal and Equal Powers: New Definitions in Modern Geometry 18141826", Revue d'histoire des mathématiques 23, pp. 71-123.

Morley, Frank (1907), "On Two Cubic Curves in Triangular Relation", Proceedings of the London Mathematical Society, 2nd ser. 4, pp. 384-392.

Moutard, Théodore (1862), "Recherches analytiques sur les polygones simultanément inscrits et circonscrits à deux coniques", in, Applications d'analyse et de géométrie, qui ont servi de principal fondement au Traité des propriétés projectives des figures, vol. 1, Paris: Mallet-Bachelier, pp. 535-560.

- (1864a), "Note sur la transformation par rayons vecteurs réciproques", Nouvelles Annales de mathématiques, 2nd ser. 3, pp. 306-309.

- (1864b), "Sur les surfaces anallagmatiques du quatrième ordre", Nouvelles Annales de mathématiques, 2nd ser. 3, pp. 536-539.

Müller, Felix (1900), Mathematisches Vokabularium: Französisch-Deutsch und DeutschFranzösisch, enthaltend die Kunstausdrücke aus der reinen und angewandten Mathematik, Leipzig: Teubner.

Nabonnand, Philippe (2015), "L'Étude des propriétés projectives des figures par Poncelet : une modernité explicitement ancrée dans la tradition", in Christian Gilain and Alexandre Guilbaud (eds.), Sciences mathématiques 1750-1850. Continuités et ruptures, Paris: CNRS Éditions, pp. 381-402.

Oswald, Nicola and Steuding, Jörg (2014), "Complex Continued Fractions: Early Work of the Brothers Adolf and Julius Hurwitz", Archive for History of Exact Sciences 68 (4), pp. 499-528. 
Pasch, Moritz (1930), Eine Selbstschilderung, Giessen: Münchowsche Universität-Druckerei. Repr. in Mitteilungen aus dem mathematischen Seminar Giessen 146 (1980), p. 1-19.

Picquet, Henry (1884), "Applications de la représentation des courbes du troisième degré à l'aide des fonctions elliptiques”, Journal de l'École polytechnique 54, pp. 31-100.

Playfair, John (1794), "On the Origin and Investigation of Porisms", Transactions of the Royal Society of Edinburgh 3, pp. 154-204.

Poncelet, Jean-Victor (1822), Traité des propriétés projectives des figures, Paris: Bachelier.

- (1862), Applications d'analyse et de géométrie, qui ont servi de principal fondement au Traité des propriétés projectives des figures, vol. 1, Paris: Mallet-Bachelier.

Richelot, Friedrich (1830), “Anwendung der elliptischen Transcendenten auf die sphärischen Polygone, welcher zugleich einem kleinen Kreise der Kugel eingeschrieben und einem andern umgesschreiben sind", Journal für die reine und angewandte Mathematik $\mathbf{5}$, pp. 250-267.

- (1849), "Ueber die Anwendung einiger Formeln aus der Theorie der elliptischen Functionen auf ein bekanntes Problem der Geometrie", Journal für die reine und angewandte Mathematik 38, pp. 353-372.

Rollet, Laurent and Nabonnand, Philippe (2013), "Un journal pour les mathématiques spéciales : les Nouvelles annales de mathématiques (1842-1927)", Bulletin de l'Union des Professeurs de Spéciale 86, pp. 5-18.

Rosanes, Jacob and Pasch, Moritz (1865), "Ueber das einem Kegelschnitte umbeschriebene und einem andern einbeschriebene Polygon", Journal für die reine und angewandte Mathematik 64, pp. 126-166.

- (1869), "Ueber eine algebraische Aufgabe, welche einer Gattung geometrischer Probleme zu Grunde liegt", Journal für die reine und angewandte Mathematik 70, pp. 169-174.

Schoute, Pieter Hendrik (1883), "Die Steinerschen Polygone", Journal für die reine und angewandte Mathematik 95, pp. 105-119, 200, 317-324.

Schröter, Heinrich (1888), Die Theorie der ebenen Kurven dritter Ordnung, Leipzig: Teubner.

Schur, Friedrich (1882), "Ueber eine besondere Classe von Flächen vierter Ordnung", Mathematische Annalen 20, pp. 254-296.

Serret, Paul (1862), "Note sur deux suites récurrentes de cercles et de sphères", Nouvelles Annales de mathématiques, 2nd ser. 1, pp. 184-187.

Simon, Max (1867), De relationibus inter constantes duarum linearum secundi ordinis, ut sit polygonum alteri inscriptum circumscriptum alteri, Berlin: Driesner.

— (1876), "Ganzzahlige Multiplication der elliptischen Functionen in Verbindung mit dem Schliessungsproblem", Journal für die reine und angewandte Mathematik 81, pp. 301323.

- (1906), Über die Entwicklung der Elementar-Geometrie im XIX. Jahrhundert, Leipzig: Teubner.

Snyder, John P. (1993), Flattening the Earth: Two Thousand Years of Map Projections, Chicago, London: The University of Chicago Press.

Staude, Otto (1883), "Ueber geodätische Polygone auf den Flächen 2. Grades", Mathematische Annalen 21, pp. 219-252.

- (1904), "Flächen 2. Ordnung und ihre Systeme und Durchdringungskurven", in, Encyklopädie der mathematischen Wissenschaften mit Einschluss ihrer Anwendungen, vol. III C 2, Leipzig: Teubner, pp. 161-256. 
Steiner, Jacob (1827/1828), "Questions proposées. Théorèmes de géométrie”, Annales de Mathématiques pures et appliquées 18, pp. 378-380.

- (1826), "Einige geometrische Betrachtungen", Journal für die reine und angewandte Mathematik 1, pp. 161-184, 252-288.

— (1827), "Geometrische Aufgaben und Lehrsätze", Journal für die reine und angewandte Mathematik 2, pp. 96-98.

- (1846), "Geometrische Lehrsätze", Journal für die reine und angewandte Mathematik 32, pp. 182-184.

Taylor, Henry Martyn (1878), "On the Porism of the Ring of Circles Touching Two Circles", Messenger of Mathematics 7, pp. 148-150.

Thomae, Johannes Karl (1895), "Ueber den Zusammenhang zwischen den Steiner'schen und den Poncelet'schen Polygonen”, Berichte über die Verhandlungen der KöniglichSächsischen Gesellschaft der Wissenschaften zu Leipzig 47, pp. 352-374.

Tobies, Renate (1994), "Mathematik als Bestandteil der Kultur: Zur Geschichte des Unternehmens Encyklopädie der mathematischen Wissenschaften mit Einschluss ihrer Anwendungen", Mitteilungen der Österreichischen Gesellschaft für Wissenschaftsgeschichte 14, pp. 1-90.

Tweddle, Ian (2000), Simson on Porisms: An Annotated Translation of Robert Simon's Posthumous Treatise on Porisms and Other Items on this Subject, London: Springer.

Vahlen, Theodor (1896), "Ueber Steiner'sche Kugelketten", Zeitschrift für Mathematik und Physik 41, pp. 153-160.

Vitrac, Bernard (1990), Euclide : Les Éléments, vol. 1. Introduction générale, livres I à IV, Paris: Presses Universitaires de France.

Volkert, Klaus (1994), "Max Simon als Historiker und Didaktiker der Mathematik", in Jürgen Schönbeck, Horst Struve, and Klaus Volkert (eds.), Der Wandel im Lehren und Lernen von Mathematik und Naturwissenschaften, vol. 1. Mathematik, Weinheim: Deutschen Studien Verlag.

Wardhaugh, Benjamin (2016), "Greek Mathematiks in English: The Work of Sir Thomas L. Heath (1861-1940)", in Volker Remmert, Martina Schneider, and Henrik Kragh Sørensen (eds.), Historiography of Mathematics in the 19th and 20th Centuries, Basel: Birkhäuser, pp. 109-122.

Weyr, Eduard (1870), "Ueber einige Sätze von Steiner und ihren Zusammenhang mit der zwei und zweigliedrigen Verwandtschaft der Grundgebilde ersten Grades", Journal für die reine und angewandte Mathematik 71, pp. 18-28.

— (1871), "Zusatz zu dem Aufsatze 'Ueber einige Sätze von Steiner und ihren Zusammenhang mit der zwei und zweigliedrigen Verwandtschaft der Grundgebilde ersten Grades",, Journal für die reine und angewandte Mathematik 73, pp. 87-93.

Weyr, Emil (1893), "Über Fünfecke, welche einer $C_{3}$ gleichzeitig ein- und umgescrhieben sind", Monatshefte für Mathematik und Physik 4, p. 120.

White, Henry S. (1906), "Triangles and Quadrilaterals Inscribed in a Conic and Circumscribed to a Conic", Annals of Mathematics 7 (4), pp. 172-176.

Wittgenstein, Ludwig (1953), Philosophical Investigations, Oxford: Basil Blackwell. English translation by Gertrude Elizabeth Anscombe. 
Wolstenholme, Joseph (1870), "On a Certain System of Trigonometrical Equations, with Applications to the Porisms of Two Coaxal Conics", The Quarterly Journal of Pure and Applied Mathematics 10, pp. 356-368.

Zacharias, Max (1913), "Elementargeometrie und elementare nicht-euklidische Geometrie in synthetischer Behandlung", in, Encyklopädie der mathematischen Wissenschaften mit Einschluss ihrer Anwendungen, vol. III A B 9, Leipzig: Teubner, pp. 859-1172. 